\title{
Detection of formaldehyde emissions from an industrial zone in the Yangtze River Delta region of China using a proton transfer reaction ion-drift chemical ionization mass spectrometer
}

\author{
Yan Ma ${ }^{1,2}$, Yiwei Diao ${ }^{2,3}$, Bingjie Zhang ${ }^{1}$, Weiwei Wang ${ }^{3}$, Xinrong Ren $^{4}$, Dongsen Yang $^{1,2,3}$, Ming Wang ${ }^{1}$, \\ Xiaowen Shi ${ }^{1,2}$, and Jun Zheng ${ }^{1,2}$ \\ ${ }^{1}$ School of Environmental Science and Engineering, Collaborative Innovation Center of Atmospheric Environment and \\ Equipment Technology, Nanjing University of Information Science and Technology, Nanjing 210044, China \\ ${ }^{2}$ Yale-NUIST Center on Atmospheric Environment, Nanjing University of Information Science \& Technology, \\ Nanjing 210044, China \\ ${ }^{3}$ Key Laboratory for Aerosol-Cloud-Precipitation of China Meteorological Administration, Department of Atmospheric \\ Physics, Nanjing University of Information Science and Technology, Nanjing 210044, China \\ ${ }^{4}$ Department of Atmospheric and Oceanic Science, University of Maryland, College Park, MD 20742, USA
}

Correspondence to: Jun Zheng (zheng.jun@ nuist.edu.cn)

Received: 7 June 2016 - Published in Atmos. Meas. Tech. Discuss.: 1 August 2016

Revised: 8 November 2016 - Accepted: 28 November 2016 - Published: 21 December 2016

\begin{abstract}
A proton transfer reaction ion-drift chemical ionization mass spectrometer (PTR-ID-CIMS) equipped with a hydronium $\left(\mathrm{H}_{3}^{+} \mathrm{O}\right)$ ion source was developed and deployed near an industrial zone in the Yangtze River Delta (YRD) region of China in spring 2015 to investigate industryrelated emissions of volatile organic compounds (VOCs). Air pollutants including formaldehyde ( $\mathrm{HCHO})$, aromatics, and other trace gases $\left(\mathrm{O}_{3}\right.$ and $\left.\mathrm{CO}\right)$ were simultaneously measured. Humidity effects on the sensitivity of the PTR-IDCIMS for $\mathrm{HCHO}$ detection were investigated and quantified. The performances of the PTR-ID-CIMS were also validated by intercomparing with offline $\mathrm{HCHO}$ measurement technique using 2,4-dinitrophenylhydrazone (DNPH) cartridges and the results showed fairly good agreement (slope $=0.81$, $\left.R^{2}=0.80\right)$. The PTR-ID-CIMS detection limit of HCHO (10 s, three-duty-cycle averages) was determined to be $0.9-$ $2.4(\mathrm{RH}=1-81.5 \%)$ parts per billion by volume (ppbv) based on 3 times the standard deviations of the background signals. During the field study, observed HCHO concentrations ranged between 1.8 and $12.8 \mathrm{ppbv}$ with a campaign average of $4.1 \pm 1.6 \mathrm{ppbv}$, which was comparable with previous $\mathrm{HCHO}$ observations in other similar locations of China. However, HCHO diurnal profiles showed few features of secondary formation. In addition, time series of both $\mathrm{HCHO}$ and
\end{abstract}

aromatic VOCs indicated strong influence from local emissions. Using a multiple linear regression fit model, on average the observed $\mathrm{HCHO}$ can be attributed to secondary formation $(13.8 \%)$, background level $(27.0 \%)$, and industryrelated emissions, i.e., combustion sources (43.2\%) and chemical productions $(16.0 \%)$. Moreover, within the plumes the industry-related emissions can account for up to $69.2 \%$ of the observed $\mathrm{HCHO}$. This work has provided direct evidence of strong primary emissions of $\mathrm{HCHO}$ from industryrelated activities. These primary $\mathrm{HCHO}$ sources can potentially have a strong impact on local and regional air pollution formation in this area of China. Given the fact that the YRD is the largest economic zone in China and is dense with petrochemical industries, primary industrial HCHO emissions should be strictly monitored and regulated.

\section{Introduction}

Formaldehyde (HCHO) has been well recognized as one of the most abundant and important carbonyls in the atmosphere (Dasgupta et al., 2005; Lei et al., 2009; Li et al., 2014; Olaguer et al., 2013; Parrish et al., 2012; Rappenglück et al., 2010). HCHO is ubiquitous in the atmosphere with a typ- 
ical near-ground concentration ranging from sub-ppbv levels in the rural area to $\sim 60 \mathrm{ppbv}$ in highly polluted regions (Finlayson-Pitts and Pitts, 1999). HCHO plays a crucial role in atmospheric photochemistry. The absorption spectrum of HCHO extends well into the UVA region and thus its photolysis rate coefficient (Reaction R1) is one of the highest among all carbonyl compounds in the atmosphere (Gratien et al., 2007). Photolysis of HCHO (Reaction R1a) can contribute substantially to the atmospheric $\mathrm{HO}_{x}$ radical $\left(\mathrm{OH}+\mathrm{HO}_{2}\right)$ budget and thus can exert great impact on the oxidative capacity of the atmosphere (Volkamer et al., 2010). Since hydrogen $\left(\mathrm{H}_{2}\right)$ is classified as an indirect greenhouse gas, the R1b channel is also of atmospheric importance and may have a non-negligible impact on global climate change (Schultz et al., 2003; Tromp et al., 2003).

$\mathrm{HCHO}+h v(\lambda<330 \mathrm{~nm}) \rightarrow \mathrm{H}+\mathrm{HCO}$

$\mathrm{HCHO}+h v(\lambda<360 \mathrm{~nm}) \rightarrow \mathrm{H}_{2}+\mathrm{CO}$

$\mathrm{HCHO}$ is considerably water soluble. Hence, HCHO may participate in either acid or base catalyzed aldolcondensation reactions in the aerosol phase to contribute to secondary organic aerosol (SOA) formation (Wang et al., 2010). Moreover, HCHO is a known carcinogen. Exposure to HCHO vapor can cause nasal and eye irritation. During exposure tests, breathing in as low as $100 \mathrm{ppbv} \mathrm{HCHO}$ may cause allergic reactions in certain populations (http: //www.atsdr.cdc.gov/toxfaqs/tfacts111.pdf).

In the background atmosphere, $\mathrm{HCHO}$ is mostly formed from photochemical oxidation of methane $\left(\mathrm{CH}_{4}\right)$ and terminal alkenes (Finlayson-Pitts and Pitts, 1999). HCHO can also be emitted directly into the air from vegetation, although its formation mechanism is not well known (Seco et al., 2007). HCHO flux measurements conducted in forest areas indicate that both plants and the ground surface can contribute to assignable $\mathrm{HCHO}$ emissions, although the magnitude is relatively small compared to the photochemical production (DiGangi et al., 2011). In contrast to biogenic HCHO sources, anthropogenic activities are often intense primary $\mathrm{HCHO}$ sources. HCHO can be produced from any incomplete combustion processes. Vehicle exhaust is believed to be the dominant primary $\mathrm{HCHO}$ sources in heavily populated urban areas (Anderson et al., 1996; Ho et al., 2012). Regardless of the types of fuel, all internal combustion engines emit considerable amounts of HCHO. Interestingly, usage of alternative fuels can substantially reduce vehicle emissions of nitrogen oxides $\left(\mathrm{NO}_{x}\right)$ but may significantly increase emissions of HCHO and other carbonyl compounds (Wagner and Wyszynski, 1996). A recent study by Rappenglück et al. (2013) suggests that currently available mobile emission models (e.g., MOBILE6 and MOVES) may significantly underestimate the $\mathrm{HCHO}$ emissions from vehicles and there is a non-negligible difference of $\mathrm{HCHO}$ emissions between lightduty and heavy-duty diesel vehicles. Nevertheless, studies have found that vehicle exhaust alone may lead to significant underestimation of the emission inventory of carbonyl compounds in Beijing (Wang et al., 2014), most likely due to the complicated but poorly understood emissions from the industrial sector (Chen et al., 2014). High concentrations of HCHO have been observed around the Houston Ship Channel area populated with petrochemical facilities (Rappenglück et al., 2010). Using an imaging differential optical absorption spectrometer, Pikelnaya et al. (2013) have detected direct HCHO emission from burning flares of the refineries in Houston. In addition to flares, desulfurization and other petrochemical processes such as catalytic cracking of refinery feed may also contribute substantially to primary $\mathrm{HCHO}$ emissions (Olaguer et al., 2013). Other industry-related activities, such as wood processing and manufacturing of insect and fungus products, also contribute substantial primary $\mathrm{HCHO}$ emissions (Garcia et al., 2006). Recent studies have demonstrated that primary carbonyl emissions from a remote oil and gasproduction region can lead to high ozone $\left(\mathrm{O}_{3}\right)$ formation in a nearby rural area (Edwards et al., 2014). Therefore, it is of practical interest to fully comprehend the detailed primary emission sources of carbonyl compounds, especially in the case of HCHO.

Various source apportionment methods have been successfully utilized to identify primary and secondary HCHO sources (Chen et al., 2014; Garcia et al., 2006; Li et al., 2014; Olaguer et al., 2013; Parrish et al., 2012; Zheng et al., 2013b). Due to the lack of carbonyl emission inventories, particularly in China, it is impractical to directly estimate $\mathrm{HCHO}$ emissions using emission factors. However, carbon monoxide $(\mathrm{CO})$, sulfur dioxide $\left(\mathrm{SO}_{2}\right)$, and toluene have been observed co-emitted with carbonyl compounds from industrial facilities at various locations and hence can serve as tracers of industrial HCHO emission (Pikelnaya et al., 2013; Rappenglück et al., 2010; Wang et al., 2015); i.e., variations of these gases are linearly associated with the primary $\mathrm{HCHO}$ emissions. Accordingly, correlation-based methods, such as the multiple linear regression fit model, can be used to quantify the relative contribution of primary industrial $\mathrm{HCHO}$ sources (Li et al., 2014).

$\mathrm{HCHO}$ can be measured by various analytical techniques (Gilpin et al., 1997; Li et al., 2005), among which proton transfer reaction mass spectrometry (PTR-MS) does not require sample pretreatments, is free from optical impairment due to heavy aerosol loading, and can potentially achieve a time resolution of a few seconds (Karl et al., 2003). It has been demonstrated that PTR-MS is particularly suitable for capturing strong point sources of volatile organic compounds (VOCs) (Zheng et al., 2013a, b). In this work, a proton transfer reaction ion-drift chemical ionization mass spectrometer (PTR-ID-CIMS) (Fortner et al., 2004; Zheng et al., 2008, 2010, 2015a) equipped with a corona discharge (CD) hydronium ion source (Zheng et al., 2015b) was developed to investigate VOC-related emissions from an industrial zone in Nanjing, China. The performance of the PTRID-CIMS was evaluated by intercomparing with the more 


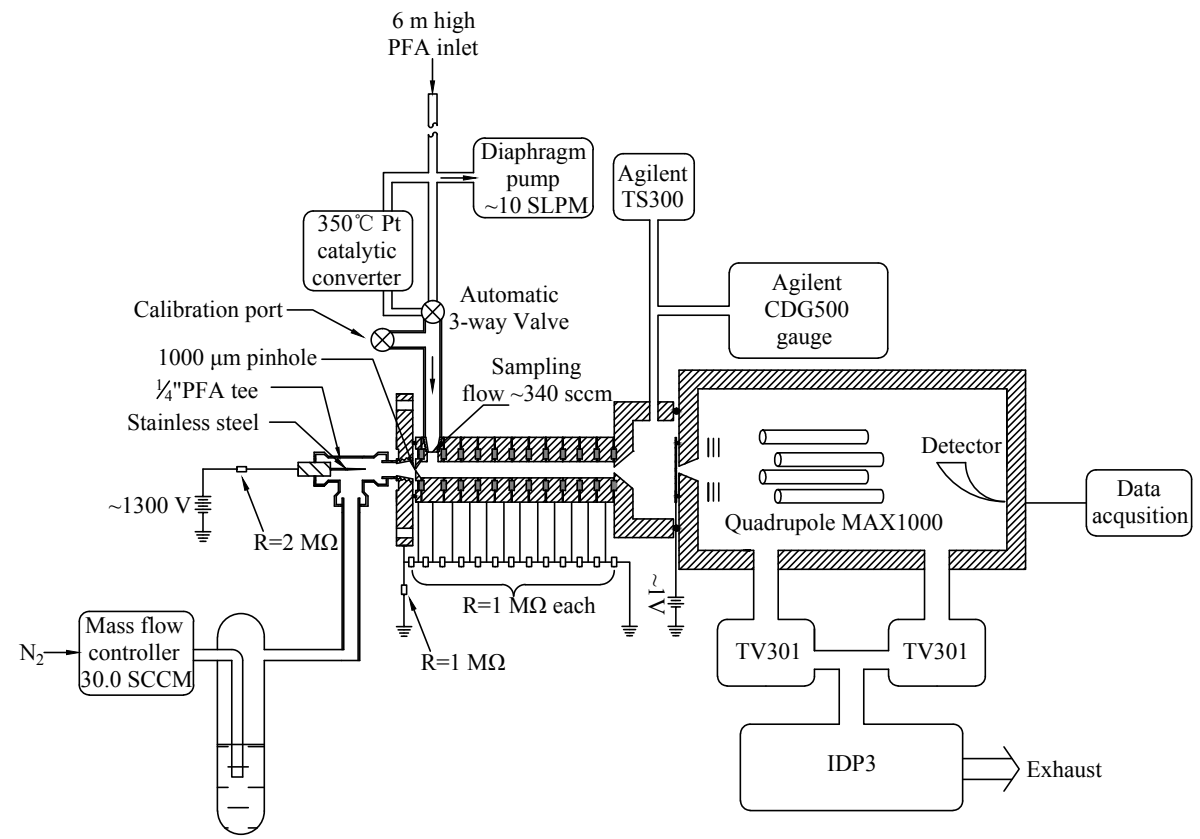

Figure 1. Schematic diagram of the proton transfer reaction ion-drift chemical ionization mass spectrometer (PTR-ID-CIMS).

established DNPH (2,4-dinitrophenylhydrazone) technique and the contribution of industry-related activities to primary $\mathrm{HCHO}$ emissions was evaluated with a multiple linear regression fit model.

\section{Experimental methods}

\subsection{Observation site}

The measurements were carried out from 15 to 30 April 2015 on the campus of the Nanjing University of Information Science and Technology (NUIST). A detailed description of the site $\left(32^{\circ} 12^{\prime} 20.8^{\prime \prime} \mathrm{N}, 118^{\circ} 42^{\prime} 19.2^{\prime \prime} \mathrm{E}\right)$ has been given in our previous work (please see Fig. 1 in Zheng et al. (2015a) for details). Briefly, the site was established by the Chinese Meteorological Administration as a training facility for meteorological observations. Meteorology parameters, including wind direction, wind speed, ambient temperature, pressure, relative humidity, and solar radiation, were continuously measured according to Chinese national standards (GB31221-2014). The site was located in the middle of two highways, i.e., G40 and G205, which were about $1.3 \mathrm{~km}$ to the west and $1.5 \mathrm{~km}$ to the east of the site, respectively. From the aromatics measurement results, we found no substantial impacts on measured $\mathrm{HCHO}$ from traffic-related emissions, which will be detailed in the discussion section. When easterly winds were dominant, the site was constantly affected by the outflow from the industry zone (Zheng et al., 2015a). All instruments were housed inside an air-conditioned trailer. The sample line was made of $6.4 \mathrm{~mm}$ OD PFA tubing and was installed on the roof of the trailer, about $6 \mathrm{~m}$ above ground level.

\subsection{PTR-ID-CIMS}

A schematic diagram of the PTR-ID-CIMS is shown in Fig. 1. The working principle of the PTR-ID-CIMS is fundamentally the same as a commercial Ionicon PTR-MS (Hansel et al., 1995). The PTR-ID-CIMS consists of a water reservoir, a point-to-surface CD ion source (Zheng et al., 2015b), a drift tube, and a quadrupole mass spectrometer (QMS) (Extrel, MAX 1000). During operation, 30.0 standard $\mathrm{cm}^{3} \mathrm{~min}^{-1}$ (SCCM) of ultrapure nitrogen $\left(\mathrm{N}_{2}\right)$ regulated by a mass flow controller (Axetris AG) was fed into the water reservoir and then carried water vapor into the $\mathrm{CD}$ ion source, where a stainless steel needle biased with $1300 \mathrm{~V}$ discharged on the wall of a $2.5 \mathrm{~cm}$ long, $6.4 \mathrm{~mm}$ OD stainless steal tubing. Generated hydronium ions $\left(\mathrm{H}_{3}^{+} \mathrm{O}\right)$ were pushed into the drift tube through a $1 \mathrm{~mm}$ diameter pinhole. The drift tube was comprised of $112.5 \mathrm{~cm}$ OD, $9.5 \mathrm{~mm}$ ID, $6.4 \mathrm{~mm}$ thick stainless steel rings that were separated from each other by $1.0 \mathrm{~mm}$ thick PTFE spacers. The metal rings were interconnected with $1.0 \mathrm{M} \Omega$ resistors. On the sidewall of the first ring was mounted a PTFE critical orifice limiting the sampling flow to be 340 SCCM. The drift tube was pumped with an Agilent TS-300 dry scroll pump and the pressure in the drift tube was 2.0 mbar, measured by an Agilent CDG-500 capacitance diaphragm pressure gauge. The voltage between any two adjacent rings was $37.0 \mathrm{~V}$, which produced an electric field of $52.9 \mathrm{~V} \mathrm{~cm}^{-1}$. The corresponding ratio of electric field $(E)$ to the buffer gas number density $(N)$, i.e., $E / N$ ratio, was 


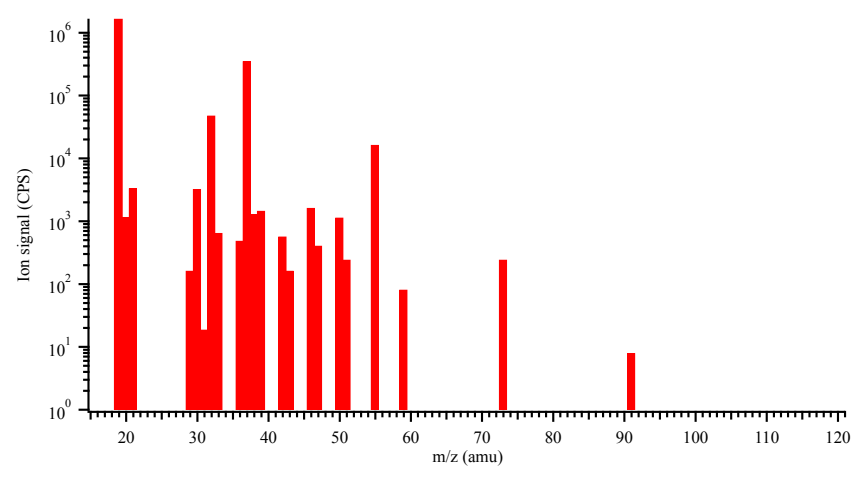

Figure 2. A typical mass spectrum produced by the PTR-ID-CIMS in the laboratory.

$108 \mathrm{Td}\left(1 \mathrm{Td}=1 \times 10^{-17} \mathrm{~V} \mathrm{~cm}^{2}\right)$. To maintain a constant reaction temperature, the drift tube was regulated at $60^{\circ} \mathrm{C}$. A $200 \mu \mathrm{m}$ pinhole (Edmund Optics) biased by $1 \mathrm{~V}$ was used to separate the drift tube from the high vacuum region that was housing the quadrupole mass analyzer and the Channeltron electron multiplier. The vacuum chamber was differentially pumped by two Agilent TV-301 turbomolecular pumps, which shared one Agilent IDP-3 dry scroll pump as the backing pump. Ambient air was delivered to the PTRID-CIMS through the $6 \mathrm{~m}$ long sample line and a diaphragm pump was used to pump the inlet at 10 standard $\mathrm{L} \mathrm{min}^{-1}$ (SLPM) and thus to minimize the sample residence time no more than $1 \mathrm{~s}$. The inlet was also heated to $\sim 60^{\circ} \mathrm{C}$ to reduce potential wall losses. Using an automatic PTFE threeway valve, background checks were conducted once every $30 \mathrm{~min}$ for $10 \mathrm{~min}$ by rerouting sample air through a $350{ }^{\circ} \mathrm{C}$ Pt catalytic converter (Zheng et al., 2013b, 2015a).

Figure 2 is a typical mass spectrum generated by the PTRID-CIMS after scanning the laboratory air by unit mass. Hydronium ion $(m / z 19)$ and its water clusters $(m / z 37, m / z 55$, $m / z 73$, and $m / z$ 91) can be observed clearly in the spectrum and are the dominant ions. Although the oxygen ion $(\mathrm{m} / \mathrm{z} 32)$ is also present, it is less than $2.5 \%$ of the primary hydronium ion $(m / z, 19)$ and thus does not interfere significantly with the PTR reactions initiated by hydronium ions. Masses 33, 42, and 59 can be respectively attributed to methanol, acetonitrile, and acetone because all of these chemicals are commonly utilized as organic solvents in the organic chemistry laboratories in our department. We want to point out that mass 33 can also originate from isotopic peak of $\mathrm{O}_{2}^{+}$with oxygen-17 $\left({ }^{17} \mathrm{OO}^{+}\right)$and protonated oxygen $\left(\mathrm{HO}_{2}^{+}\right)$, which, however, are also present during background checks using a catalytic converter and thus both of them will be subtracted from the methanol signal. Mass 59 can also originate from propanal and glyoxal. However, since both propanal and especially glyoxal are significantly more reactive than acetone in the atmosphere, both of them typically contribute less than $10 \%$ of the mass 59 signal (de Gouw and Warneke, 2007). The other peaks were most likely due to the chemicals and their fragments originated from various chemistry experiments in the building.

In theory, the PTR-ID-CIMS worked essentially in the same way as an Ionicon PTR-MS in VOC detections. However, the PTR-ID-CIMS was developed with an intention to do more than positive ion chemical ionization analysis and thus it was equipped with a bipolar ion detection system. It can be readily converted into a negative ion CIMS. With the proper ion chemistry scheme, the PTR-ID-CIMS can be used to detect not only VOCs but also ammonia $\left(\mathrm{NH}_{3}\right)$ (Nowak et al., 2006), nitrous acid (HONO) (Pinto et al., 2014), and nitric acid $\left(\mathrm{HNO}_{3}\right)$ (Zheng et al., 2008). In the future, the drift tube can also be modified to adapt an atmospheric pressure interface (API) to do sulfuric acid measurements (Zheng et al., 2010). Another significant difference between the PTRID-CIMS and the Ionicon PTR-MS was the inlet system. In the PTR-ID-CIMS air samples were introduced into the drift tube through a critical orifice instead of a long $(>1 \mathrm{~m})$ $1.5 \mathrm{~mm}$ OD capillary PEEK tubing used in the Ionicon PTRMS. We found our inlet setup had the advantages of faster time response and lower wall losses and especially suited for sticky gas measurements, such as $\mathrm{NH}_{3}$ (Zheng et al., 2015a). In this work, we focus on the measurement and analysis of VOC emissions in the Yangtze River Delta (YRD) region using the PTR-ID-CIMS, especially from industry-related sources.

\subsection{HCHO Measurement with PTR-ID-CIMS}

The PTR-ID-CIMS was operated in the single ion monitor (SIM) mode; i.e., a series of masses were sequentially detected by the PTR-ID-CIMS. The QMS was set to measure each mass for $2 \mathrm{~s}$ and then pause for $2 \mathrm{~s}$ after switching to a new setting to account for the slew time of the QMS power supply. More than 40 masses were measured during each measurement cycle and it took about $3 \mathrm{~min}$ to finish one duty cycle. HCHO was detected at $m / z$ 31. Because the proton affinity of $\mathrm{HCHO}$ is slightly higher than water, Reaction (R2) is reversible.

$\mathrm{H}_{3}^{+} \mathrm{O}+\mathrm{HCHO} \leftrightarrow \mathrm{H}^{+} \mathrm{HCHO}+\mathrm{H}_{2} \mathrm{O}$

Therefore, the HCHO measurement using PTR-ID-CIMS was strongly affected by the water concentration in the drift tube. This water dependency has been investigated in details previously and the sensitivity dependence on water in $\mathrm{HCHO}$ detection can be evaluated as the following (Inomata et al., 2008; Jobson and McCoskey, 2010; Schripp et al., 2010; Warneke et al., 2011; Wisthaler et al., 2008; Zheng et al., 2013b):

$$
\begin{aligned}
& {\left[\mathrm{H}^{+} \mathrm{HCHO}\right]} \\
& \quad=\frac{k[\mathrm{HCHO}]\left[\mathrm{H}_{3}^{+} \mathrm{O}\right]\left(1-e^{-\left(k\left[\mathrm{H}_{3}^{+} \mathrm{O}\right]+k^{\prime}\left[\mathrm{H}_{2} \mathrm{O}\right]\right)} t\right)}{k\left[\mathrm{H}_{3}^{+} \mathrm{O}\right]+k^{\prime}\left[\mathrm{H}_{2} \mathrm{O}\right]},
\end{aligned}
$$


where $k$ and $k^{\prime}$ are the forward and reverse reaction rate coefficients of Reaction (R2), respectively, and $t$ is the ionmolecule reaction time. Given $\left[\mathrm{H}_{2} \mathrm{O}\right] \gg\left[\mathrm{H}_{3}^{+} \mathrm{O}\right]$, Eq. (1) can be simplified and rearranged as Eq. (2):

$$
\frac{\left[\mathrm{H}^{+} \mathrm{HCHO}\right]}{\left[\mathrm{H}_{3}^{+} \mathrm{O}\right][\mathrm{HCHO}]}=\frac{k\left(1-e^{-k^{\prime}\left[\mathrm{H}_{2} \mathrm{O}\right]} t\right)}{k^{\prime}\left[\mathrm{H}_{2} \mathrm{O}\right]} .
$$

The left-hand side of the equation indicates that $\mathrm{H}_{3}^{+} \mathrm{O}$ normalized $\mathrm{H}^{+} \mathrm{HCHO}$ counts rate signal (normalized counts $\mathrm{s}^{-1}$, NCPS) with respect to $1 \mathrm{ppbv}$ of $\mathrm{HCHO}$ (NCPS $\mathrm{ppbv}^{-1}$ ) or that the sensitivity of the PTR-ID-CIMS to $\mathrm{HCHO}$ is a function of water vapor concentration inside the drift tube in the form of Warneke et al. (2011):

$y=\frac{A}{x}\left(1-e^{-B x}\right)$,

where $x$ is the water vapor concentration, $A=k / k^{\prime}$, and $B=k^{\prime} t$. Therefore, the sensitivity of the PTR-ID-CIMS to $\mathrm{HCHO}$ at certain humidity can be evaluated according to Eq. (2) if the parameters $A$ and $B$ are known. Figure 3 shows a plot of the PTR-ID-CIMS response to HCHO standards under various ambient humidities. Each data point of Fig. 3 was the result of one set of calibration, which will be described in details in the following section. The corresponding water vapor concentration was determined from sample air humidity and the ion source carrier flow humidity. The values of $A$ and $B$ were inferred from curve fitting using Eq. (3) as the fitting function. The linear correlation coefficient between the original and fitted values was determined to be 0.82 . In addition, given that the reaction temperature and $E / N$ in this work were kept constant (i.e., $60^{\circ} \mathrm{C}$ and $108 \mathrm{Td}$ ) and the reduced ion mobility of $\mathrm{H}_{3}^{+} \mathrm{O}$ in air was taken as $2.76 \mathrm{~cm}^{2} \mathrm{~V}^{-1} \mathrm{~s}^{-1}$ (de Gouw et al., 1997), the ion-molecule reaction time was determined to be about $103 \mu$ s. Accordingly, $k$ and $k^{\prime}$ of Reaction (R2) were also evaluated from $A$ and $B$ with values of $0.84 \times 10^{-9} \mathrm{~cm}^{3}$ molecule ${ }^{-1} \mathrm{~s}^{-1}$ and $2.0 \times 10^{-11} \mathrm{~cm}^{3}$ molecule ${ }^{-1} \mathrm{~s}^{-1}$, respectively. The energy dependency of $k$ and $k^{\prime}$ has been investigated by Hansel et al. (1997). It was demonstrated that the reverse reaction channel, $k^{\prime}$, increased significantly with increasing mean relative kinetic energy (KE) of the reactants while $k$ only showed slightly negative energy dependency. KE under the reaction conditions of this work was calculated according to the method as described by Hansel et al. (1997). The reduced ion mobility of $\mathrm{H}^{+} \mathrm{HCHO}$ in air was assumed to be similar as that of $\mathrm{H}_{3}^{+} \mathrm{O} \cdot \mathrm{H}_{2} \mathrm{O}\left(2.27 \mathrm{~cm}^{2} \mathrm{~V}^{-1} \mathrm{~s}^{-1}\right)$ (de Gouw et al., 1997), since they have a similar molecular size. Therefore, the KEs associated with the forward and the reverse reactions were respectively determined to be $0.12 \mathrm{eV}$ and $0.10 \mathrm{eV}$. The corresponding $k$ and $k^{\prime}$ measured by Hansel et al. (1997) were $1.4 \times 10^{-9}$ and $1.1 \times 10^{-11} \mathrm{~cm}^{3}$ molecule ${ }^{-1} \mathrm{~s}^{-1}$, respectively. Evidently, the inferred values from Fig. 3 agreed fairly well with the literature values.

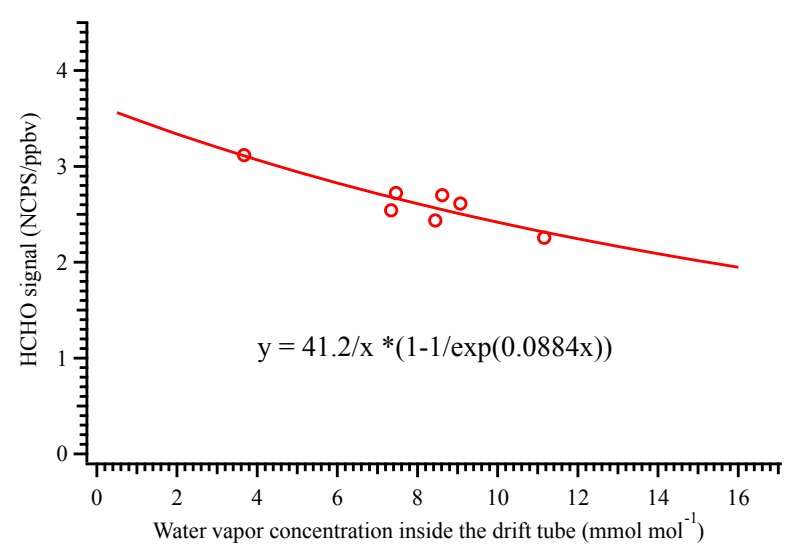

Figure 3. The response of the PTR-ID-CIMS to HCHO standards (in the units of counts $\mathrm{s}^{-1} \mathrm{ppbv}^{-1} \mathrm{HCHO}$ standard per million $\mathrm{H}_{3}^{+} \mathrm{O}$ ion, NCPS ppbv ${ }^{-1}$ ) as a function of water vapor concentration inside the drift tube. The correlation is in the form of $y=\frac{A}{x}\left(1-e^{-B x}\right)$, deduced from Eq. (1), where $A$ is the ratio between the forward $(k)$ and reverse $\left(k^{\prime}\right)$ reaction rate coefficient and $B$ is the product of $k^{\prime}$ and the ion-molecule reaction time $t$.

In Fig. 3 much less variation in instrument sensitivity was observed in this work than the previous studies (Vlasenko et al., 2010). The most likely reason is that the ion source of the PTR-ID-CIMS used humidified pure nitrogen as carrier gas. The nitrogen flow rate (30.0 SCCM) was much higher than the water vapor flow rate used by a typical Ionicon PTR-MS and more importantly all of the humidified nitrogen was sucked into the drift tube instead of being pumped away in the case of PTR-MS. Consequently, the background water concentration in the drift tube of the PTR-ID-CIMS was significantly higher than a typical PTR-MS. As indicated by Fig. 5 of Vlasenko et al. (2010), the instrument sensitivity will change substantially when the water content changes slightly from the completely dry condition. Therefore, the relatively high background water content in the PTR-IDCIMS can lead to decreased sensitivity during "dry" calibrations, which can explain the much lower variation in sensitivity observed in this work.

\subsection{PTR-ID-CIMS calibration}

PTR-ID-CIMS calibrations were performed by mixing gaseous VOC standards (Apel-Reimer Environmental, USA) into zero air through the calibration port. The VOC standard flow rate was controlled by a metal-seal 100 SCCM mass flow controller (UNIT, UFC-1260A). The mixing ratios of the target VOCs inside the cylinder are on the order of a few hundreds of ppbv with an uncertainty of $<5 \%$; e.g., the mixing ratios of benzene and toluene were 208 and $157 \mathrm{ppbv}$, respectively. Before each calibration, the PFA tubing to deliver the VOC standard gas was passivated by flowing a few SCCM of VOC standards through it for at least $8 \mathrm{~h}$. The zero air was normally generated in situ by passing ambient air 
through the catalytic converter and its flow rate was controlled by a critical orifice (as shown in Fig. 1), which was precisely quantified by a Gillibrator (Sensidyne Gilian). U1tra pure nitrogen was also used in place of the zero air to conduct calibrations under the dry condition. The HCHO standard concentration in the cylinder was verified by the DNPH cartridge measurements with a value of $284 \pm 2 \mathrm{ppbv}$ (based on three independent measurements). Background signals were checked before and after the HCHO standard additions using the catalytic converter. The PTR-ID-CIMS was also operated in the SIM mode during calibrations. Similar to the field measurement cycle, the integration time at each mass was set to $2 \mathrm{~s}$ and the time interval between two consecutive masses was also set to $2 \mathrm{~s}$. Each calibration cycle contained 48 masses, including $m / z 21\left(\mathrm{H}_{3}^{18} \mathrm{O}^{+}\right), m / z 25$ (system background), $m / z 30\left(\mathrm{NO}^{+}\right), m / z 32\left(\mathrm{O}_{2}^{+}\right), m / z 37\left(\mathrm{H}_{3} \mathrm{O}^{+} \mathrm{H}_{2} \mathrm{O}\right)$, and other VOC standard gases. It took about 3 min to complete one measurement cycle. Figure 4a shows the time series of a typical HCHO calibration. Since the nitrogen-15 isotopic peak of $\mathrm{NO}\left({ }^{15} \mathrm{NO}^{+}\right)$also contributes to the signal at $m / z 31$, relatively high background signals were observed in Fig. 4a. In addition, because the quadrupole mass filter can normally achieve unit mass separation, $m / z 31$ signals were also slightly interfered by the tail from the relatively strong adjacent oxygen peak $\left(\mathrm{O}_{2}^{+}\right)$, which was about 1 to $2 \%$ of the $\mathrm{H}_{3}^{+} \mathrm{O}$ intensity. Although ${ }^{15} \mathrm{NO}^{+}$interference can be removed from the real HCHO signal by background subtraction, to accurately reflect $\mathrm{HCHO}$ background signal variations, $0.37 \%$ (Hoffmann and Stroobant, 2007) of the signal of $m / z 30$ (not shown in Fig. 4a) was subtracted from HCHO background check signals before the background noise was evaluated. Each insert in Fig. 4 is the corresponding calibration curve with background signal subtracted. To fully characterize the humidity effects on its performance, the PTR-ID-CIMS was also calibrated under various relative humidity conditions (1.0, 17.5, 29.0, 47.0, 62.5, and $81.5 \%$ ) using pure air as the carrier gas. The relative humidity of the VOC standards was achieved by passing the carrier gas through a water bubbler similar to the one used in Zheng et al. (2015a). Three to four consecutive calibrations were performed at each RH setting. The results are displayed in Fig. 5. It is clearly shown that higher instrument sensitivity (i.e., NCPS per ppbv HCHO) is associated with lower RH setting. The instrument sensitivity and the corresponding detection limit (DL) (based on 3 times the standard deviations of the background signals) at each RH setting were evaluated from each individual calibration. Furthermore, the instrument precision at each RH setting was assessed by the variations of both the instrument sensitivity and the DL among repeated calibrations. The results showed that on average the PTR-ID-CIMS DL of HCHO varied from $0.9 \mathrm{ppbv}$ for dry condition to $2.4 \mathrm{ppbv}$ for $81.5 \% \mathrm{RH}$ at room temperature. Among all RH settings $(<81.5 \%)$ the variations of the instrument sensitivity and the DL were less than 17 and $16 \%$ of the average values, respectively. Therefore, for the worst case, the HCHO measurement uncertainty in this work should be $<18 \%$, including the $1 \%$ uncertainty associated with the HCHO standard concentrations. The performances of various $\mathrm{HCHO}$ measurement techniques including this work have been listed in Table 1. Evidently, the sensitivity of PTR-ID-CIMS for HCHO detection was comparable to other PTR-MS-based techniques and was fast enough to capture pollution episodes with a timescale of at least a few hours.

Calibrations of benzene (Fig. 4b) and toluene (Fig. 4c) were conducted using the VOC standard mixture simultaneously with the HCHO calibrations. For three-duty-cycle averages, the calibration factors and detection limits were, respectively, $41.2 \mathrm{NCPS} \mathrm{ppbv}^{-1}$ and $0.06 \mathrm{ppbv}$ for benzene and $40.0 \mathrm{NCPS} \mathrm{ppbv}^{-1}$ and $0.07 \mathrm{ppbv}$ for toluene. In a similarly way as the case of $\mathrm{HCHO}$, we determined the uncertainties of benzene and toluene measurements to be less than 8.7 and $11.0 \%$ (including the $5 \%$ uncertainty associated with the VOC standard concentration) in this work.

\subsection{DNPH HCHO measurements}

Carbonyls including HCHO were also measured with the DNPH method followed the US EPA method TO-11A. Cartridges coated with DNPH (Agela Technologies, Tianjin) were used to scrub carbonyls from the ambient air samples and then analyzed by high-performance liquid chromatography (HPLC) (Waters, Alliance e2695) equipped with a Diamonsil C-18 column $(5 \mu \mathrm{m}, 250 \mathrm{~mm}$ by $4.6 \mathrm{~mm})$. The cartridge was attached to the front end of a $6.4 \mathrm{~mm}$ OD PFA tubing that was bound to the inlet of the PTR-ID-CIMS. A potassium iodide (KI) cartridge was also installed in the front of the DNPH cartridge to remove ozone. Ambient air was pulled into the cartridges by a diaphragm pump and the flow rate was set to 0.53 SLPM by a critical orifice, which was calibrated with the Gillibrator. The sampling time varied from 0.6 to $2 \mathrm{~h}$ during the campaign depending on the ambient $\mathrm{HCHO}$ concentrations. The sampled cartridges were stored in Teflon bags at $4{ }^{\circ} \mathrm{C}$ right after sampling. Note that a few high $\mathrm{O}_{3}$ episodes were encountered during the measurement period with a maximum concentration of about $140 \mathrm{ppbv}$, which can potentially interfere with DNPH samples. However, as demonstrated by the US EPA, the KI cartridges can efficiently remove $125-200 \mathrm{ppbv} \mathrm{O}_{3}$ from air samples for up to $100000 \mathrm{ppbv} h$ with a requirement of minimum moisture level of $10 \% \mathrm{RH}$ (https://www3.epa.gov/ttnamti1/files/ ambient/airtox/to-11ar.pdf, accessed October 2016). Given the relative high RH conditions during the campaign period, $\mathrm{O}_{3}$ should not interfere with our DNPH HCHO measurements.

All cartridge samples were processed within 2 weeks from dates samples were collected. Each sample was first slowly eluted with $5 \mathrm{~mL}$ acetonitrile (HPLC grade) and $20.0 \mu \mathrm{L}$ of the extract solution was injected into the HPLC 
Table 1. Performance intercomparison of various $\mathrm{HCHO}$ measurement techniques.

\begin{tabular}{|c|c|c|c|c|}
\hline Measurement technique & Limit of detection & Time resolution & Precision & Reference \\
\hline DNPH HPLC & $13.4 \mathrm{pptv}$ & $1 \mathrm{~h}$ & $2.9 \%$ & Fung and Grosjean (1981) \\
\hline Long pathlength Fourier transform infrared spectroscopy & $6 \mathrm{ppbv}$ & $5 \mathrm{~min}$ & $\pm 4 \mathrm{ppbv}$ & Tuazon et al. (1981) \\
\hline Hantzsch reaction/fluorometric flow injection analysis & $0.1 \mu \mathrm{M}^{\mathrm{a}}$ & $80 \mathrm{~s}$ & $5 \%$ & Dong and Dasgupta (1987) \\
\hline Liquid-trapping/fluorescence detection & $0.2 \mathrm{ppbv}$ & $80 \mathrm{~s}$ & $5 \%$ & Kelly and Fortune (1994) \\
\hline Laser-induced fluorescence & $36 \mathrm{pptv}$ & $1 \mathrm{~s}$ & $20 \%$ & Cazorla et al. (2015) \\
\hline Differential optical absorption spectroscopy & $4.5 \mathrm{ppbv}$ & $12-15 \mathrm{~min}$ & $30 \%$ & Lawson et al. (1990) \\
\hline Tunable diode laser absorption spectroscopy & $0.25 \mathrm{ppbv}$ & $3 \min$ & $20 \%$ & Harris et al. (1989) \\
\hline Quantum cascade laser spectrometer & $0.3 \mathrm{ppbv}$ & $1 \mathrm{~min}$ & $20 \%$ & Herndon et al. (2007) \\
\hline \multirow{4}{*}{ Ionicon PTR-MS } & $1-2 \mathrm{ppbv}$ & $5 \mathrm{~s}$ & $20 \%$ & Karl et al. (2003) \\
\hline & $0.2-0.5 \mathrm{ppbv}$ & $5 \mathrm{~s}$ & $25 \%$ & Inomata et al. (2008) \\
\hline & $78-95 \mathrm{pptv}$ & $5 \mathrm{~s}$ & $<24 \%$ b & Jobson and McCoskey (2010) \\
\hline & $0.1-0.3 \mathrm{ppbv}$ & $1 \mathrm{~s}$ & $30 \%$ & Warneke et al. (2011) \\
\hline PTR-ID-CIMS & $0.9-2.4 \mathrm{ppbv}$ & $10 \mathrm{~s}$ & $<18 \%$ & This work ${ }^{\mathrm{c}}$ \\
\hline
\end{tabular}

Table 2. Parameters of the multiple linear regression fit and the linear correlation coefficient $\left(R^{2}\right)$ for the measured and source-apportioned $\mathrm{HCHO}$ in Eq. (4). $\beta_{1}$ denotes the portion of $\mathrm{HCHO}$ from photochemical production. $\beta_{2}, \beta_{3}$, and $\beta_{4}$ are the emission ratios of $\mathrm{HCHO}$ with respect to $\mathrm{CO}$, benzene, and toluene, respectively. $\beta_{5}$ represents $\mathrm{HCHO}$ concentration in the background atmosphere.

\begin{tabular}{llllll}
\hline$\beta_{1}\left(\mathrm{ppbv} \mathrm{ppbv}^{-1}\right)$ & $\beta_{2}\left(\mathrm{ppbv} \mathrm{ppbv}^{-1}\right)$ & $\beta_{3}\left(\mathrm{ppbv} \mathrm{ppbv}^{-1}\right)$ & $\beta_{4}\left(\mathrm{ppbv} \mathrm{ppbv}^{-1}\right)$ & $\beta_{5}(\mathrm{ppbv})$ & $R^{2}$ \\
\hline $0.0118 \pm 0.0012$ & $0.00116 \pm 0.000055$ & $0.218 \pm 0.014$ & $0.196 \pm 0.016$ & $1.00 \pm 0.10$ & 0.52 \\
\hline
\end{tabular}

for analysis. Acetonitrile-water solution (40-60\%) was used as a gradient mobile phase and the flow rate was set to $1.2 \mathrm{~mL} \mathrm{~min}^{-1}$. Separated carbonyls were detected by its absorption at $360 \mathrm{~nm}$ by a UV detector (Waters 2998). Calibration was conducted with standard solution (Supelco, USA) containing $15 \mathrm{DNPH}$ derivatives of carbonyls, including formaldehyde, acetaldehyde, acrolein, acetone, propionaldehyde, crotonaldehyde, butyraldehyde, benzaldehyde, isovaleraldehyde, valeraldehyde, o-tolualdehyde, m-tolualdehyde, p-tolualdehyde, hexanaldehyde, and 2,5dimethylbenzaldehyde. The dynamic range of a five-point calibration of $\mathrm{HCHO}$ spanned from 0.05 to $1.0 \mu \mathrm{g} \mathrm{mL}^{-1}$ with a linear correlation coefficient of 0.9998 . For a $2 \mathrm{~h}$ sampling time, the DL of $\mathrm{HCHO}$ was $0.00037 \mu \mathrm{g} \mathrm{mL}^{-1}$, corresponding to 25 parts trillion ${ }^{-1}$ volume $^{-1}$ (pptv) at $25^{\circ} \mathrm{C}$, $1.01 \times 10^{5} \mathrm{~Pa}$. The uncertainty of the DNPH method determined from three independent calibrations was less than $3.6 \%$.

\subsection{Other trace gas measurements}

$\mathrm{CO}$ (Thermo Scientific, model 48i) and $\mathrm{O}_{3}$ (Thermo Scientific, model 49i) were also measured at the site. Their operation and calibration procedures followed the manufacturer's instructions and have been detailed in previous work (Zheng et al., 2015a).

\section{Results and discussion}

\subsection{Overall observation results}

Meteorological parameters including wind direction and wind speed, relative humidity (RH) and ambient temperature $(T)$, and solar radiation are shown in Fig. 6a-c. During the observation period, the weather was mostly clear with occasional precipitation events on 18, 19, 27, and 28 April. RH and $T$ showed typical anticorrelation in their diurnal variations. No gusty wind was experienced during the observation period and the average wind speed was $\sim 2.1 \mathrm{~m} \mathrm{~s}^{-1}$.

The time series of $\mathrm{O}_{3}, \mathrm{CO}$, benzene $\left(\mathrm{C}_{6} \mathrm{H}_{6}\right)$, toluene $\left(\mathrm{C}_{7} \mathrm{H}_{8}\right)$, and $\mathrm{HCHO}$ (three-duty-cycle averages) are shown in Fig. 6d-f, respectively. Also shown in Fig. 6f (black dots) are the HCHO results from the DNPH cartridge measurements. The gaps in the trace gas measurements were due to either power interruptions or instrument calibrations. High $\mathrm{HCHO}$ concentrations up to $12.8 \mathrm{ppbv}$ (three-duty-cycle averages) were observed in a few pollution episodes. All observed gases showed no obvious diurnal variations, except $\mathrm{O}_{3}$, which is a secondary air pollutant mainly formed from photochemical processes (Finlayson-Pitts and Pitts, 1999). Although $\mathrm{HCHO}$ was often considered as an intermediate oxidation product of VOCs, such as olefins and $\mathrm{CH}_{4}$, we did not observe noticeable diurnal pattern of $\mathrm{HCHO}$ in this work either. However, positive correlations $\left(R^{2}=0.2-0.4\right)$ were found among $\mathrm{HCHO}$, aromatics, and $\mathrm{CO}$ and significantly better correlations $\left(R^{2}=0.4-0.6\right)$ among these species could 

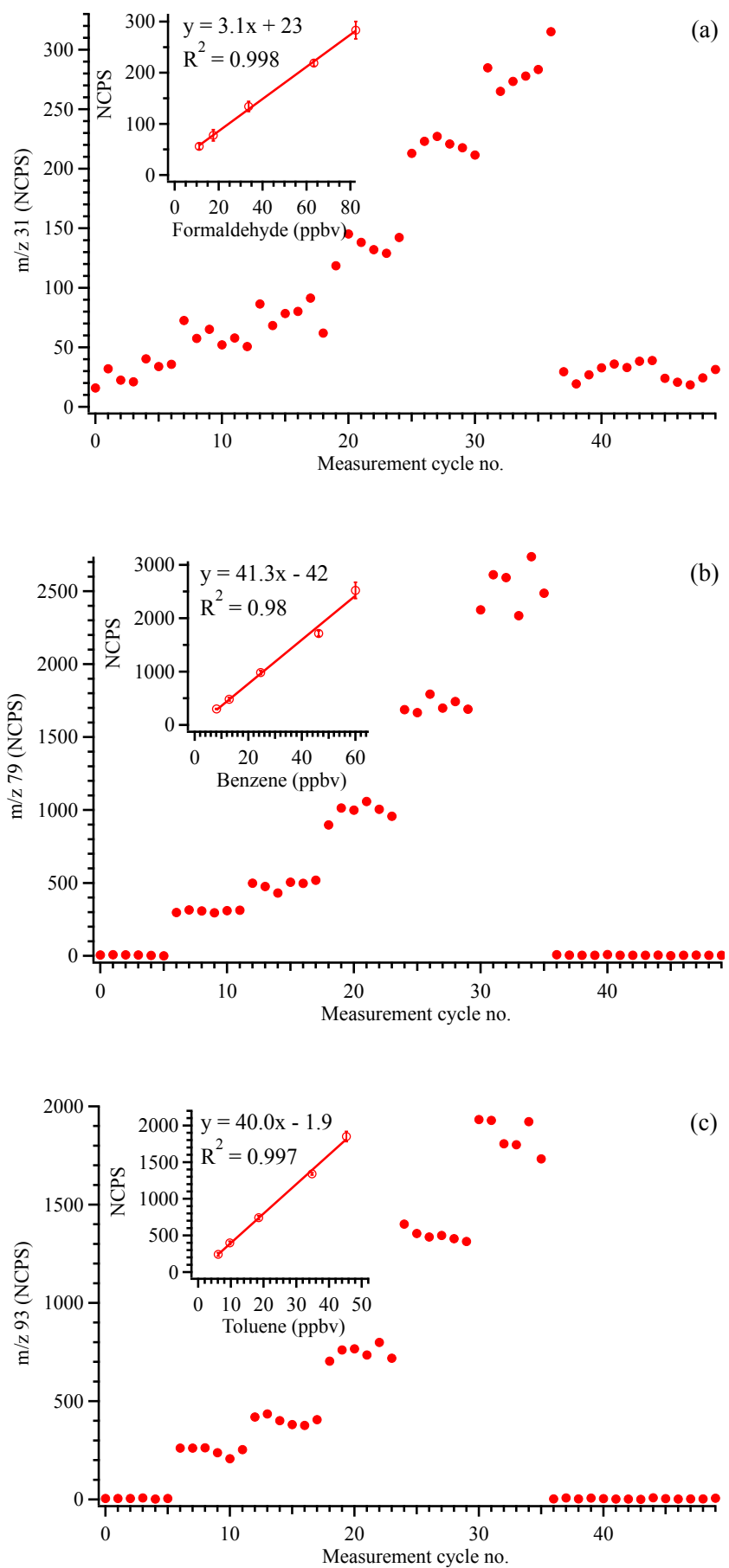

Figure 4. Time series of a typical set of calibration of HCHO (a), benzene (b), and toluene (c). The insert in each panel is the calibration curve obtained from the corresponding calibration data.

be found within individual plumes, which strongly suggests that primary emissions were responsible for the observed high concentrations of HCHO. In addition, all heavy pollution episodes observed in this campaign were associated with

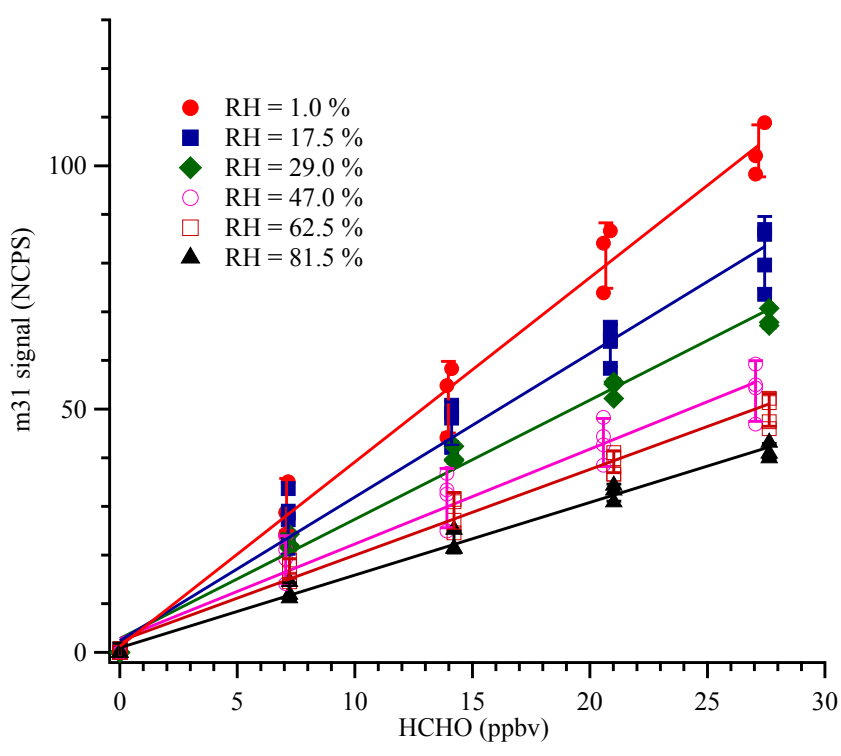

Figure 5. $\mathrm{HCHO}$ calibrations conducted at $\mathrm{RH}=1-81.5 \%$. Three or four repeated calibrations were performed at each RH setting. The averaged background signals have been subtracted from all calibration data sets. The linear fitting lines are based on the average of each group of calibrations at one RH setting and the corresponding error bars represent 1 standard deviation of each group of calibrations.

easterly wind, which can be demonstrated by the rose plots of $\mathrm{HCHO}, \mathrm{CO}$, benzene, toluene, and $\mathrm{O}_{3}$ in Fig. 7.

The temporal variations of $\mathrm{HCHO}$ in this work also differed distinctly from that observed at the Tijuana site during the Cal-Mex 2010 campaign (Zheng et al., 2013b). Although both sites were located in the vicinity of industrial zones, the type of industry in Tijuana was dominated by electronic industries, which normally utilize large quantities of organic solvents (such as methanol, acetone, and ethyl acetate) for electronic parts cleaning during lithography processing (Zheng et al., 2013a). Assisted by the stronger subtropical solar radiation in May/June 2010 during Cal-Mex than in April 2015 during this study, stronger solar radiation can result in more $\mathrm{HCHO}$ formation from VOC oxidation in Tijuana. In contrast, the industrial zone in Nanjing is a rather intensive point source on a regional scale as indicated by Fig. 1 of Zheng et al. (2015a). It normally takes several hours for the plumes from the industrial zone to arrive at the site and thus it is reasonable to assume that the plumes are well mixed. The VOC pollution episodes observed in this work typically lasted for more than a few hours, which was consistent with previous ammonia and amine measurements conducted at the same site (Zheng et al., 2015a). The atmospheric lifetime of $\mathrm{HCHO}$ and aromatics are also on the order of at least a few hours. Therefore, we are confident that the 3 min time resolution should be sufficient to capture the variabilities of VOC plumes in this study. 


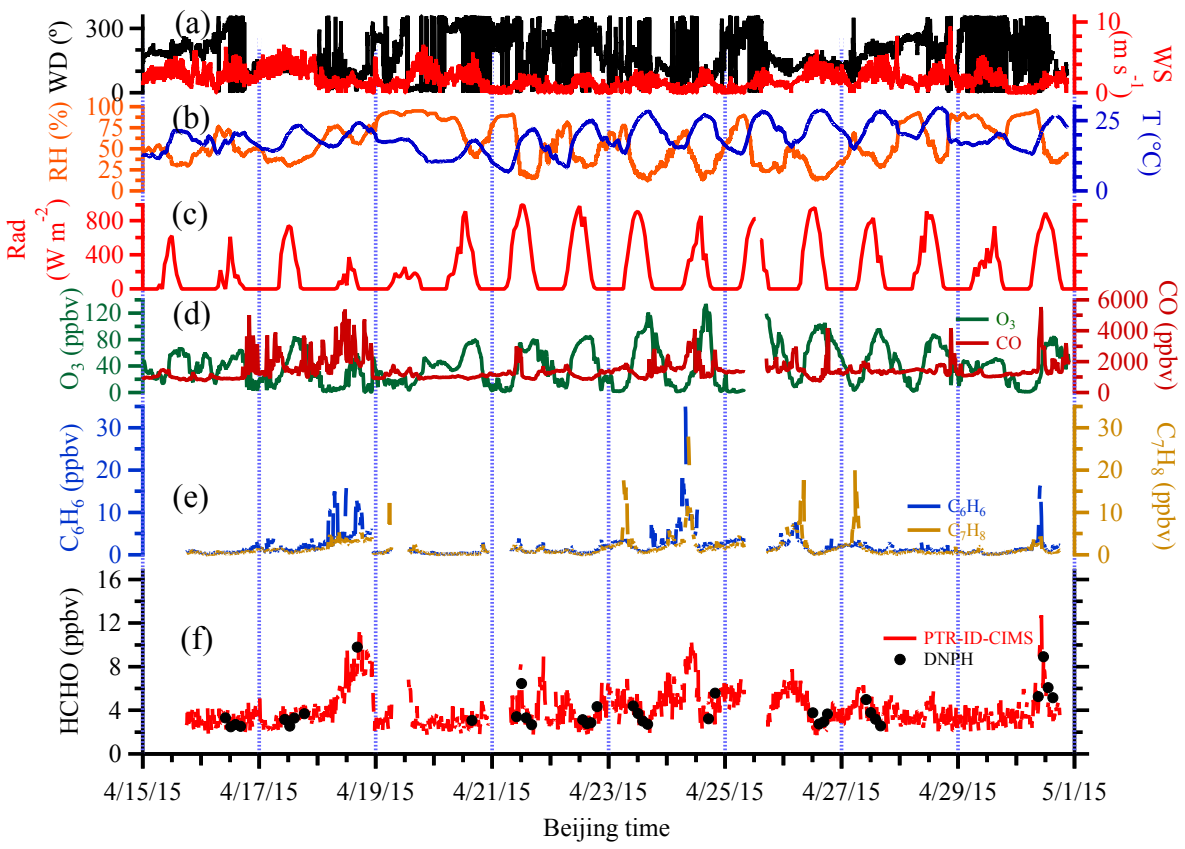

Figure 6. Time series of meteorological parameters (wind, RH, $T$, and solar radiation) (a, b and c), trace gases $\left(\mathrm{O}_{3}\right.$ and $\left.\mathrm{CO}\right)(\mathbf{d})$, benzene $\left(\mathrm{C}_{6} \mathrm{H}_{6}\right)$ and toluene $\left(\mathrm{C}_{7} \mathrm{H}_{8}\right)(\mathbf{e})$, and HCHO (f). The black dots in (e) are DNPH cartridge measurements of HCHO.

\subsection{A case study}

To illustrate the performance of the PTR-ID-CIMS in more details and to establish a clear connection between VOC plumes and primary industrial emissions, we chose the measurements on 18 April for a case study. On 18 April, it was mostly cloudy with scattered light rain. Therefore, secondary formation of $\mathrm{HCHO}$ was substantially suppressed. Figure 8 displays the wind direction and wind speed (Fig. 8a), $m / z$ 37/19 and RH (Fig. 8b), $\mathrm{O}_{3}$ and $\mathrm{CO}$ (Fig. 8c), $m / z 79$ and $m / z 93$ in NCPS (Fig. 8d), and $m / z 31$ in NCPS (Fig. 8e). It is evident that all air pollutants shown in Fig. 8 were substantially elevated in the plume but exhibit different variation profiles with periods significantly longer than the measurement duty cycle (about $3 \mathrm{~min}$ ). These fine structures in pollutant time-series indicate that these species were originated from the same area but might be associated with different industrial activities.

It is evident that humidity inside the PTR-ID-CIMS did not change significantly during background checks. Figure $8 \mathrm{~d}$ and $8 \mathrm{e}$ are the time series of $m / z 31, m / z 79$, and $\mathrm{m} / z$ 93 raw data. The background signals of $\mathrm{m} / z 31$ appear to be independent of ambient RH. We also want to point out that there is a significant difference between this work and that of Warneke et al. (2011). Warneke et al. (2011) conducted an airborne measurement of HCHO. Their PTR-MS would experience rapid humidity and pressure changes when the flight altitude changed from ground level to the free troposphere as shown in their Fig. 3c. The diurnal variation of $m / z 37 / 19$ in this work was about 0.2 to 0.24 and no sig- nificant background changes were observed, which is consistent with the results of Fig. 3c in Warneke et al. (2011). From 10:00 LT on 18 April, there was a persistent easterly wind with wind speed varying within a few meters per second. Meanwhile, significant increase of $\mathrm{HCHO}$ was observed at the site. In particular, after 19:00 LT HCHO apparently anticorrelated with wind speed. At about 23:00 LT wind direction suddenly switched to westerly wind and wind speed increased to $3-5 \mathrm{~m} \mathrm{~s}^{-1}$, bringing in cleaner air masses to the site. HCHO suddenly decreased to 2 ppbv. This observation was also consistent with the rose plots in Fig. 7. Evidently, HCHO observed on the night of 18 April can only be explained by primary sources other than automobile emissions.

\subsection{Intercomparison with DNPH cartridge measurements}

The PTR-ID-CIMS HCHO measurements were intercompared with and verified by the well-established DNPH method. Since the sampling time of the DNPH cartridges was much longer than $10 \mathrm{~min}$, the CIMS data were averaged based on the time stamp for the DNPH cartridge measurements for the intercomparisons. Overall, both measurements agreed with each other fairly well (Fig. 6f). Figure 9 shows a scatter plot of PTR-ID-CIMS versus DNPH with a slope of 0.81 and an intercept of $0.66\left(R^{2}=0.80\right.$, based on orthogonal distance regression). Based on the laboratory calibrations conducted with both $\mathrm{N}_{2}$ and air (at various levels of $\mathrm{RH}$ ), we found that the uncertainty of PTR-ID-CIMS HCHO measurements was within $18 \%$ and that of he DNPH measure- 

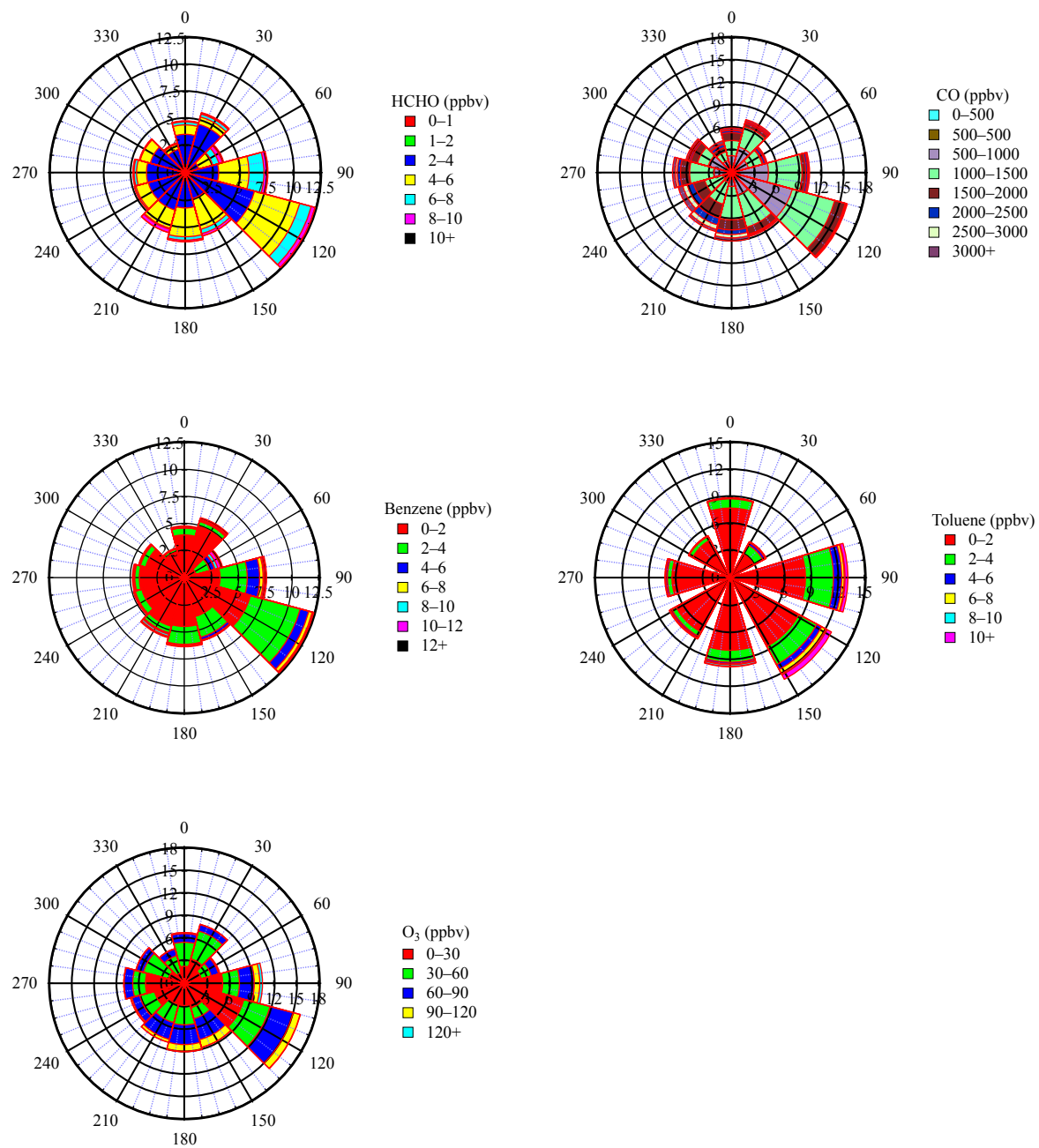

Figure 7. Rose plots of $\mathrm{HCHO}, \mathrm{CO}$, benzene, toluene, and $\mathrm{O}_{3}$. The radius represents the percentage of each air pollutant within a certain mixing ratio range. The spread angle denotes the wind direction.

ments was within $3.6 \%$. Therefore, it is reasonable to believe that the observed discrepancy between these two data sets can be explained by the combined measurement uncertainties and the higher background level in the PTR-ID-CIMS measurements.

\subsection{Determination of industrial emissions}

As the observation site is located less than $10 \mathrm{~km}$ away from the east of an industrial zone, the site was constantly experiencing plumes originated from various industrial activities, such as crude oil refining, plastic and rubber syntheses, and pesticide productions. Since benzene, toluene, and other aromatics are heavily used in many chemical syntheses, benzene and toluene are mass produced in the industrial zone by both catalytic cracking of petroleum fractions and coal carbonization. It is clearly shown in Fig. 8d that toluene and benzene peaks often did not concur simultaneously, indicating that they were emitted from different facilities. This is also consistent with the relatively weak correlations $\left(R^{2}=0.2-\right.$ 0.4 ) among individual species observed within the measurement period. Flue gases generated at these facilities were usually incinerated before they were discharged into the atmosphere. In fact many flares could be visually identified within the industrial zone. Both $\mathrm{HCHO}$ and $\mathrm{CO}$ were produced during incomplete combustion processes and direct evidence of $\mathrm{HCHO}$ emissions from flares have been confirmed by previous observations at oil refineries in Houston, Texas (Pikelnaya et al., 2013). Although it is well known that $\mathrm{HCHO}$ and $\mathrm{CO}$ were present in vehicle exhaust, the benzene to toluene ratio within $\mathrm{CO}$ plumes was determined to be $1.7 \pm 1.0$ and significantly higher than 0.5 , an indicator of automobile emissions (Hoque et al., 2008), suggesting that these air masses were not dominated by vehicle exhaust and thus most of the benzene and toluene observed in this work were not likely co-emitted by vehicle exhausts. Therefore, $\mathrm{HCHO}, \mathrm{CO}$, benzene, and toluene were likely 


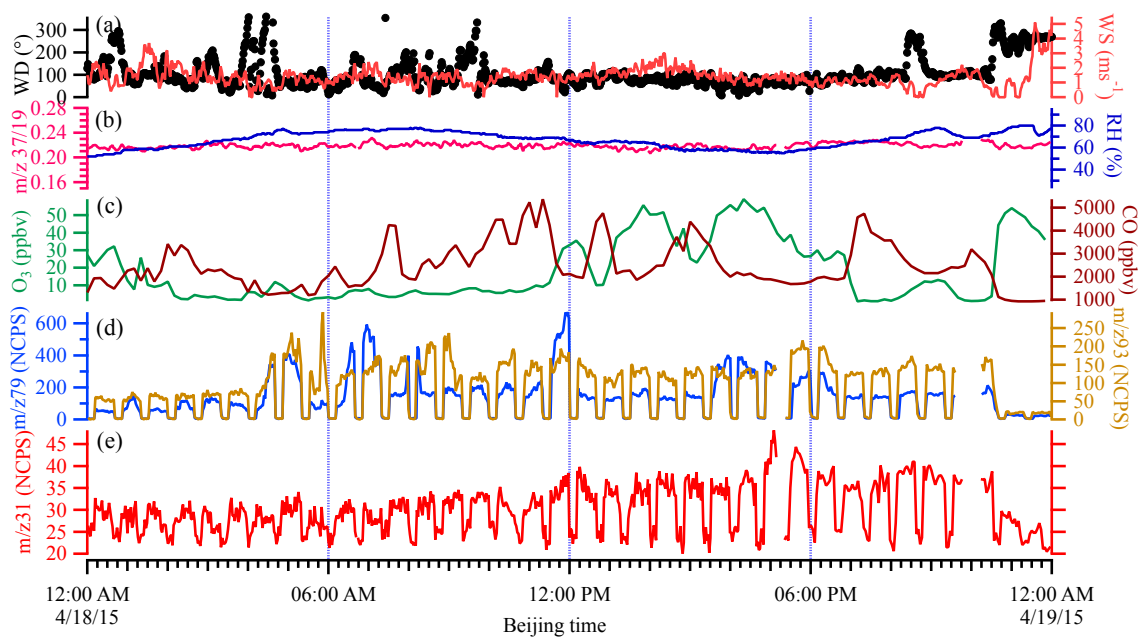

Figure 8. Time series of wind direction (WD) and wind speed (WS) (a), $m / z 37 / 19$ ratio and $\mathrm{RH}$ (b), $\mathrm{O}_{3}$ and $\mathrm{CO}$ (c), $m / z 79$ and $m / z$, 93 (d), and $m / z 31$ signal (e) on 18 April 2015. The dips in (d) and (e) are the periods when background checks were made.

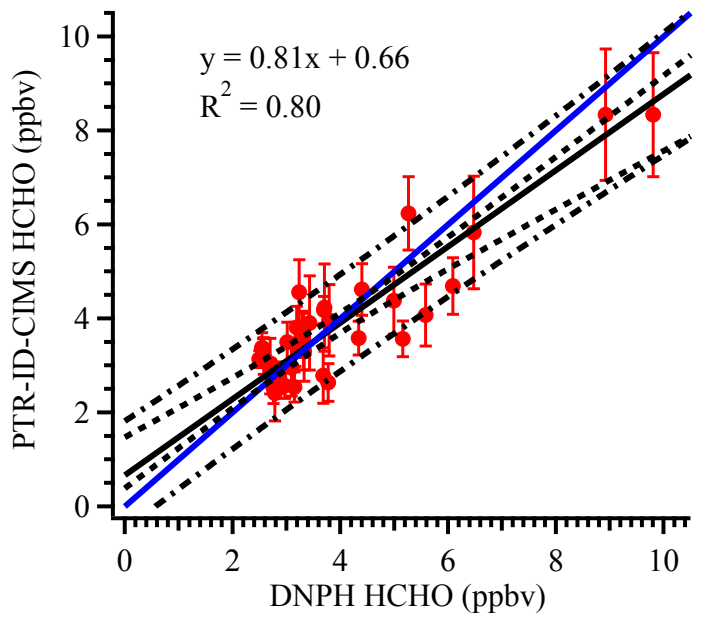

Figure 9. Linear correlation between PTR-ID-CIMS and DNPH measurements of $\mathrm{HCHO}$. The blue trace represents the $1: 1$ guideline. The black solid line is the linear fit based on orthogonal distance regression. The dashed line and the dot-dashed line denote the $95 \%$ confidence interval band and the $95 \%$ prediction band, respectively. The error bars indicate 1 standard deviation of PTRID-CIMS data within the corresponding DNPH sample collection time.

co-emitted from the industrial zone, although they may be originated from different industrial processes and transportrelated activities, such as the heavy-duty trucks operating in the vicinity of the industrial zone. Thus both benzene and toluene were selected as tracers of petrochemical-industryrelated sources and $\mathrm{CO}$ was selected as the tracer of any combustion processes including flares and vehicle exhaust. Since $\mathrm{O}_{3}$ was from secondary formation, $\mathrm{O}_{3}$ was used to represent secondary HCHO. Accordingly, the observed $\mathrm{HCHO}$ was ap- portioned by a multiple linear regression fit model (Eq. 4):

$$
\begin{aligned}
C_{\mathrm{HCHO}} & =\beta_{1} \times C_{\mathrm{O}_{3}}+\beta_{2} \times C_{\mathrm{CO}}+\beta_{3} \times C_{\text {Benzene }} \\
& +\beta_{4} \times C_{\text {Toluene }}+\beta_{5},
\end{aligned}
$$

where $C_{\mathrm{HCHO}}, C_{\mathrm{CO}}, C_{\mathrm{Benzene}}$, and $C_{\text {Toluene }}$ are measured mixing ratios of $\mathrm{HCHO}, \mathrm{O}_{3}, \mathrm{CO}$, benzene, and toluene, respectively. $\beta_{1}, \beta_{2}, \beta_{3}, \beta_{4}$, and $\beta_{5}$ are coefficients obtained from the multiple linear regression fit. $\beta_{1}$ denotes the portion of $\mathrm{HCHO}$ from photochemical production. $\beta_{2}, \beta_{3}$, and $\beta_{4}$ are the emission ratios of $\mathrm{HCHO}$ with respect to $\mathrm{CO}$, benzene, and toluene, respectively. $\beta_{5}$ represents $\mathrm{HCHO}$ concentration in the background atmosphere. According to previous work conducted at a rural site in the YRD region (Wang et al., 2015), the background level of HCHO was constrained to $1.00 \mathrm{ppbv}$ to represent the regional conditions. The multiple linear regression fit analysis was performed with a userdefined fitting function (in the Igor Pro (version 6.36) software package with the same form as Eq. 4). The data used for analysis were the same three-duty-cycle-averaged data set as that presented in Fig. 6 . The fitting process was initiated by assigning all five parameters $\left(\beta_{1}-\beta_{5}\right)$ with an initial value of 0.1 . After the first run the fitting process was reiterated with the fitting results obtained from the previous run, except that $\beta_{5}$ was constrained to $1 \mathrm{ppbv}$ by default to reflect the regional background conditions. After three iterations, the fitting results did not change from the previous run significantly and the associated standard deviations of the fitted parameters were very close to or less than 0.1 . At that point, we considered the fitting results to be acceptable. To verify the usage of $1.00 \mathrm{ppbv}$ as the background $\mathrm{HCHO}$ level, we also have performed a series of multiple linear regressions with constrained background levels ranging from 0.5 to $1.7 \mathrm{ppbv}$. The corresponding $R^{2}$ ranged from 0.43 to 0.53 . In all cases, the parameters of $\beta_{3}$ and $\beta_{4}$ in Eq. (4) did not change sub- 


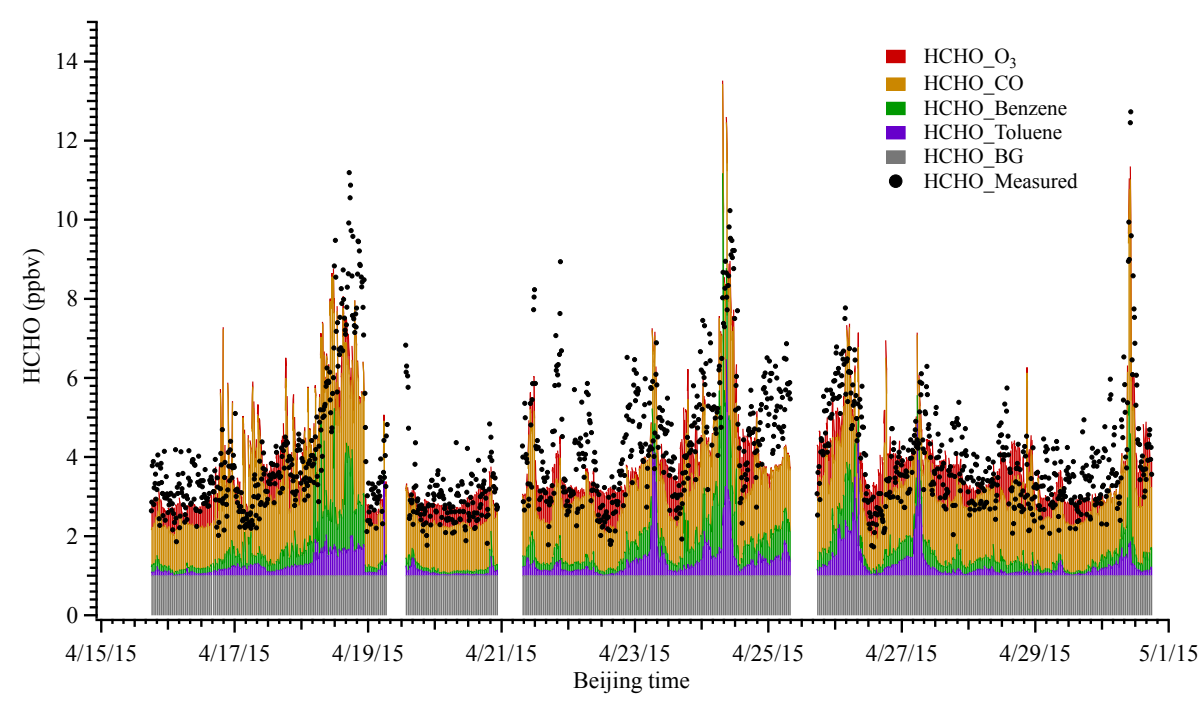

Figure 10. Comparisons of the measured $\mathrm{HCHO}$ and source-apportioned $\mathrm{HCHO}$ from the multiple linear regression fit. Measured $\mathrm{HCHO}$ is denoted by black dots and contributions from different sources are shown as color-coded bars.

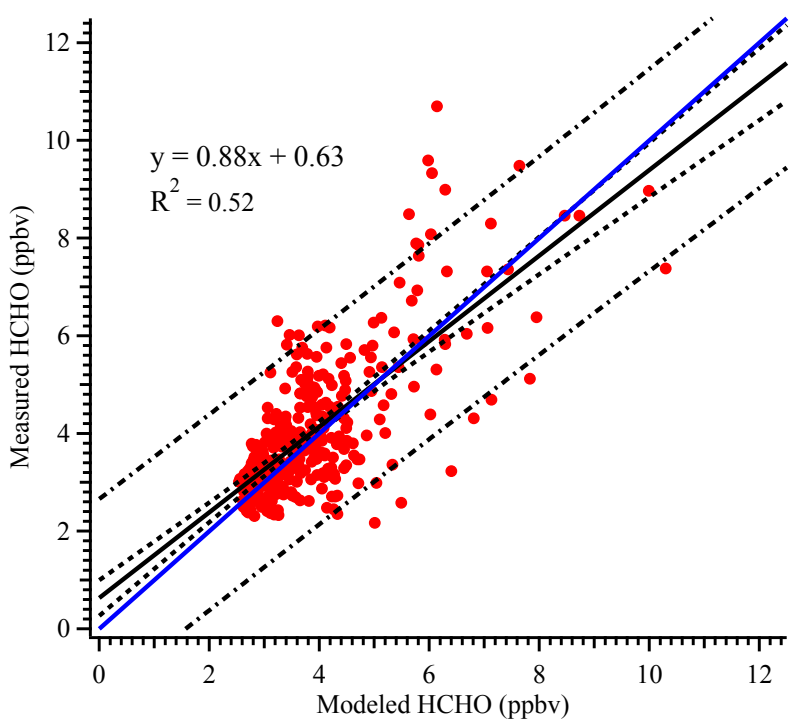

Figure 11. Linear correlation between the approximated and measured HCHO concentrations. Both data sets are synchronized into $1 \mathrm{~h}$ temporal resolutions. The blue trace represents the $1: 1$ guideline. The black solid line is the linear fit based on orthogonal distance regression. The dashed line and the dot-dashed line denote the $95 \%$ confidence interval band and the $95 \%$ prediction band, respectively.

stantially and remained the dominant terms. Since $1.00 \mathrm{ppbv}$ HCHO background level was supported by previous work (Wang et al., 2015), we thus preferred 1.00 ppbv as the constrained background level.

The fitting results are listed in Table 2. The sourceapportioned and measured $\mathrm{HCHO}$ time series are shown in Fig. 10. In general, the approximated results can cap- ture the trends of measured HCHO profiles fairly well, especially during the pollution episodes. A linear regression fit (Fig. 11) between approximated and measured HCHO shows reasonable agreement with a slope of 0.88 and $R^{2}$ of 0.52 . Based on a Student $t$ test, the measured and approximated $\mathrm{HCHO}$ values are not significantly different from each other ( $p$ value $=0.15)$ at a 0.05 significance level. The relative contributions of different sources to ambient $\mathrm{HCHO}$ are also tabulated in Table 3. Throughout the campaign period, secondary formation accounted for the smallest portion of the observed HCHO regardless within or out of the pollution episodes. The contribution associated with background level of HCHO accounted for about 22 to $29 \%$ of the total HCHO. CO, benzene, and toluene represented various industry-related activities, such as oil refineries, petrochemical syntheses, power generations, flares, and transportation, which overall contributed substantially $(59.2 \%)$ to the total HCHO budget; this portion reaches $69.2 \%$ when only pollution episodes are considered. The possible reason was that the observation site in this work was in the vicinity of the primary emission sources, which constantly emitted a large quantity of HCHO into the air. These sources were so strong that they can dominate the local photochemical production of $\mathrm{HCHO}$ and suppress the typical diurnal variations of $\mathrm{HCHO}$. In theory, $\mathrm{CO}$ and aromatics also represented industry-related vehicle emissions in this work, which may account for a significant portion of the vehicle fleet emission in the studied area. However, to specify the portion of vehicles emission cannot be achieved by the current available tracers. The positive correlations between $\mathrm{HCHO}$ and these aforementioned air pollutants established a statistical link between $\mathrm{HCHO}$ and industrial activities. The relatively weak correlation of $R^{2}=0.52$ was most likely due to the complexity of the petro- 
Table 3. Relative contributions (\%) of different sources to the observed HCHO calculated using the multiple linear regression model. Pollution episodes are defined as periods when $\mathrm{HCHO}$ concentration was higher than the campaign average, i.e., $4.1 \mathrm{ppbv}$.

\begin{tabular}{lrrrrrrr}
\hline & & \multicolumn{3}{c}{ Industry-related emission } & & \\
\cline { 3 - 5 } Secondary & $\left(\mathrm{O}_{3}\right)$ & $\mathrm{CO}$ & Benzene & Toluene & Sum of industrial emission & Background \\
\hline $\begin{array}{l}\text { Campaign } \\
\text { average }\end{array}$ & $13.8 \%$ & $43.2 \%$ & $9.4 \%$ & $6.6 \%$ & $59.2 \%$ & $27.0 \%$ \\
\hline $\begin{array}{l}\text { Pollution } \\
\text { episodes }\end{array}$ & $8.8 \%$ & $42.5 \%$ & $15.1 \%$ & $11.6 \%$ & $69.2 \%$ & $22.0 \%$ \\
\hline $\begin{array}{l}\text { Non-pollution } \\
\text { period }\end{array}$ & $16.1 \%$ & $43.6 \%$ & $6.7 \%$ & $4.3 \%$ & $54.6 \%$ & $29.3 \%$ \\
\hline
\end{tabular}

chemical industry. Many organic synthesis processes may also lead to $\mathrm{HCHO}$ emissions. These tracers used in this work may not represent all processes that contributed to $\mathrm{HCHO}$ emissions. More studies are needed to further investigate the potential primary sources of $\mathrm{HCHO}$ in the industrial zone and to fully characterize industrial VOCs emissions.

\section{Conclusions}

High concentrations of $\mathrm{HCHO}$ were observed using a custom-built PTR-ID-CIMS at a suburban site in Nanjing, China, near an industrial zone, typical in the YRD region. The humidity dependency of the PTR-ID-CIMS sensitivity to $\mathrm{HCHO}$ was evaluated by systematic calibrations. The PTR-ID-CIMS measurement of $\mathrm{HCHO}$ was verified by the US EPA recommended offline DNPH method (TO-11A). Within the observation period, HCHO ranged between 1.8 and $12.8 \mathrm{ppbv}$ with a campaign average of $4.1 \pm 1.6 \mathrm{ppbv}$, which was comparable with previous $\mathrm{HCHO}$ observations in other similar locations. Temporal variations of $\mathrm{HCHO}$ showed no clear correlation with $\mathrm{O}_{3}$, indicating the presence of strong primary point sources of HCHO. All high HCHO episodes observed in this study were associated with air masses originated from the east of the observation site where the industry zone is located and populated with heavy industrial facilities especially petrochemical-related manufacturers. Furthermore, other primary air pollutants including CO, benzene, and toluene were simultaneously measured within the plumes and showed significant correlations with HCHO. Benzene, toluene, and other aromatics were commonly used and mass produced in petrochemical industries (such as catalytic cracking of petroleum fractions and coal carbonization) and hence were excellent tracers of petrochemical processes. Both $\mathrm{CO}$ and $\mathrm{HCHO}$ can be produced during incomplete combustions, such as flares and vehicle exhaust, and thus $\mathrm{CO}$ can be considered a tracer of any combustion processes. However, the benzene to toluene ratio was found significantly higher than 0.5 in this work, indicating that vehicle exhaust may not be a major contributor to $\mathrm{HCHO}$. Using $\mathrm{O}_{3}$, $\mathrm{CO}$, benzene, and toluene as tracers, a multiple linear regres- sion analysis revealed that secondary formation, industryrelated activities (flares, various petrochemical productions, and transportation), and the background atmosphere respectively contributed $13.8,59.2$, and $27.0 \%$ to the observed HCHO. Moreover, within the plumes the portion of industryrelated emissions can account for up to $69.2 \%$ of the observed HCHO. This work has provided direct evidence of strong primary emissions of $\mathrm{HCHO}$ from industry-related activities in China. These primary HCHO sources can potentially have strong impact on local and regional air pollution formation. Given the fact that the YRD region is the largest economic zone in China and is dense with petrochemical industries, primary industrial $\mathrm{HCHO}$ emissions should be fully investigated in this area. $\mathrm{HCHO}$ emission ratios associated with individual sources are especially needed.

\section{Data availability}

The PTR-ID-CIMS data used in this work are available from the authors upon request (zheng.jun@ nuist.edu.cn).

Acknowledgements. This work was supported by the National Natural Science Foundation of China (grant no. 41275142, 21377059, 41675126, and 41575122), National Key Research and Development Project (2016YFC0202400), and Jiangsu Provincial Specially Appointed Professors Foundation.

Edited by: A. Zahn

Reviewed by: two anonymous referees

\section{References}

Anderson, L. G., Lanning, J. A., Barrell, R., Miyagishima, J., Jones, R. H., and Wolfe, P.: Sources and sinks of formaldehyde and acetaldehyde: An analysis of Denver's ambient concentration data, Atmos. Environ., 30, 2113-2123, doi:10.1016/13522310(95)00175-1, 1996.

Cazorla, M., Wolfe, G. M., Bailey, S. A., Swanson, A. K., Arkinson, H. L., and Hanisco, T. F.: A new airborne laser-induced fluores- 
cence instrument for in situ detection of formaldehyde throughout the troposphere and lower stratosphere, Atmos. Meas. Tech., 8, 541-552, doi:10.5194/amt-8-541-2015, 2015.

Chen, W. T., Shao, M., Lu, S. H., Wang, M., Zeng, L. M., Yuan, B., and Liu, Y.: Understanding primary and secondary sources of ambient carbonyl compounds in Beijing using the PMF model, Atmos. Chem. Phys., 14, 3047-3062, doi:10.5194/acp-14-30472014, 2014.

Dasgupta, P. K., Li, J. Z., Zhang, G. F., Luke, W. T., McClenny, W. A., Stutz, J., and Fried, A.: Summertime ambient formaldehyde in five US metropolitan areas: Nashville, Atlanta, Houston, Philadelphia, and Tampa, Environ. Sci. Technol., 39, 4767-4783, doi:10.1021/es048327d, 2005.

de Gouw, J. and Warneke, C.: Measurements of volatile organic compounds in the Earth's atmosphere using proton-transferreaction mass spectrometry, Mass Spectrom. Rev., 26, 223-257, 2007.

de Gouw, J. A., Krishnamurthy, M., Bierbaum, V. M., and Leone, S. R.: Measured and calculated mobilities of cluster ions drifting in helium and in nitrogen, Int. J. Mass Spectrom., 167, 281-289, 1997.

DiGangi, J. P., Boyle, E. S., Karl, T., Harley, P., Turnipseed, A., Kim, S., Cantrell, C., Maudlin, R. L., Zheng, W., Flocke, F., Hall, S. R., Ullmann, K., Nakashima, Y., Paul, J. B., Wolfe, G. M., Desai, A. R., Kajii, Y., Guenther, A., and Keutsch, F. N.: First direct measurements of formaldehyde flux via eddy covariance: implications for missing in-canopy formaldehyde sources, Atmos. Chem. Phys., 11, 10565-10578, doi:10.5194/acp-1110565-2011, 2011

Dong, S. and Dasgupta, P. K.: Fast fluorometric flow injection analysis of formaldehyde in atmospheric water, Environ. Sci. Technol., 21, 581-588, doi:10.1021/es00160a009, 1987.

Edwards, P. M., Brown, S. S., Roberts, J. M., Ahmadov, R., Banta, R. M., deGouw, J. A., Dube, W. P., Field, R. A., Flynn, J. H., Gilman, J. B., Graus, M., Helmig, D., Koss, A., Langford, A. O., Lefer, B. L., Lerner, B. M., Li, R., Li, S.-M., McKeen, S. A., Murphy, S. M., Parrish, D. D., Senff, C. J., Soltis, J., Stutz, J., Sweeney, C., Thompson, C. R., Trainer, M. K., Tsai, C., Veres, P. R., Washenfelder, R. A., Warneke, C., Wild, R. J., Young, C. J., Yuan, B., and Zamora, R.: High winter ozone pollution from carbonyl photolysis in an oil and gas basin, Nature, 514, 351354, doi:10.1038/nature13767, 2014.

Finlayson-Pitts, B. J. and Pitts, J. N.: Chemistry of the upper and lower atmosphere: theory, experiments and applications, Academic Press, San Diego, California, xxii, 969 pp., 1999.

Fortner, E. C., Zhao, J., and Zhang, R. Y.: Development of ion driftchemical ionization mass spectrometry, Anal. Chem., 76, 54365440, doi:10.1021/Ac0493222, 2004.

Fung, K. and Grosjean, D.: Determination of nanogram amounts of carbonyls as 2,4-dinitrophenylhydrazones by high-performance liquid chromatography, Anal. Chem., 53, 168-171, doi:10.1021/ac00225a009, 1981 .

Garcia, A. R., Volkamer, R., Molina, L. T., Molina, M. J., Samuelson, J., Mellqvist, J., Galle, B., Herndon, S. C., and Kolb, C. E.: Separation of emitted and photochemical formaldehyde in Mexico City using a statistical analysis and a new pair of gas-phase tracers, Atmos. Chem. Phys., 6, 4545-4557, doi:10.5194/acp-64545-2006, 2006.
Gilpin, T., Apel, E., Fried, A., Wert, B., Calvert, J., Zhang, G. F., Dasgupta, P., Harder, J. W., Heikes, B., Hopkins, B., Westberg, H., Kleindienst, T., Lee, Y. N., Zhou, X. L., Lonneman, W., and Sewell, S.: Intercomparison of six ambient $\left[\mathrm{CH}_{2} \mathrm{O}\right]$ measurement techniques, J. Geophys. Res.-Atmos., 102, 21161-21188, doi:10.1029/97jd01314, 1997.

Gratien, A., Nilsson, E., Doussin, J. F., Johnson, M. S., Nielsen, C. J., Stenstrom, Y., and Picquet-Varrault, B.: UV and IR absorption cross-sections of HCHO, HCDO, and DCDO, J. Phys. Chem. A, 111, 11506-11513, doi:10.1021/jp074288r, 2007.

Hansel, A., Jordan, A., Holzinger, R., Prazeller, P., Vogel, W., and Lindinger, W.: Proton-transfer reaction mass-spectrometry - online trace gas-analysis at the ppb level, Int. J. Mass Spectrom., 149, 609-619, 1995.

Hansel, A., Singer, W., Wisthaler, A., Schwarzmann, M., and Lindinger, W.: Energy dependencies of the proton transfer reactions $\mathrm{H}_{3} \mathrm{O}^{+}+\mathrm{CH}_{2} \mathrm{O} \leftrightarrow \mathrm{CH}_{2} \mathrm{OH}^{+}+\mathrm{H}_{2} \mathrm{O}^{*}$, Int. J. Mass Spectrom., 167, 697-703, doi:10.1016/s0168-1176(97)00128-6, 1997.

Harris, G. W., Mackay, G. I., Iguchi, T., Mayne, L. K., and Schiff, H. I.: Measurements of formaldehyde in the troposphere by tunable diode laser absorption spectroscopy, J. Atmos. Chem., 8, 119137, doi:10.1007/bf00053718, 1989.

Herndon, S. C., Zahniser, M. S., Nelson, D. D., Shorter, J., McManus, J. B., Jiménez, R., Warneke, C., and de Gouw, J. A.: Airborne measurements of $\mathrm{HCHO}$ and $\mathrm{HCOOH}$ during the New England Air Quality Study 2004 using a pulsed quantum cascade laser spectrometer, J. Geophys. Res.-Atmos., 112, D10S03, doi:10.1029/2006JD007600, 2007.

Ho, S. S. H., Ho, K. F., Lee, S. C., Cheng, Y., Yu, J. Z., Lam, K. M., Feng, N. S. Y., and Huang, Y.: Carbonyl emissions from vehicular exhausts sources in Hong Kong, J. Air Waste Manage., 62, 221-234, doi:10.1080/10473289.2011.642952, 2012.

Hoffmann, E. D. and Stroobant, V.: Mass Spectrometry - Principles and Applications, third edition ed., John Wiley \& Sons, Ltd, 457466, 2007.

Hoque, R. R., Khillare, P. S., Agarwal, T., Shridhar, V., and Balachandran, S.: Spatial and temporal variation of BTEX in the urban atmosphere of Delhi, India, Sci. Total Environ., 392, 30-40, doi:10.1016/j.scitotenv.2007.08.036, 2008.

Inomata, S., Tanimoto, H., Kameyama, S., Tsunogai, U., Irie, H., Kanaya, Y., and Wang, Z.: Technical Note: Determination of formaldehyde mixing ratios in air with PTR-MS: laboratory experiments and field measurements, Atmos. Chem. Phys., 8, 273 284, doi:10.5194/acp-8-273-2008, 2008.

Jobson, B. T. and McCoskey, J. K.: Sample drying to improve HCHO measurements by PTR-MS instruments: laboratory and field measurements, Atmos. Chem. Phys., 10, 1821-1835, doi:10.5194/acp-10-1821-2010, 2010.

Karl, T., Jobson, T., Kuster, W. C., Williams, E., Stutz, J., Shetter, R., Hall, S. R., Goldan, P., Fehsenfeld, F., and Lindinger, W. Use of proton-transfer-reaction mass spectrometry to characterize volatile organic compound sources at the La Porte super site during the Texas Air Quality Study 2000, J. Geophys. Res. Atmos., 108, 4508, doi:10.1029/2002JD003333, 2003.

Kelly, T. J. and Fortune, C. R.: Continuous Monitoring of Gaseous Formaldehyde Using an Improved Fluorescence Approach, Int. J. Environ. An. Ch., 54, 249-263, doi:10.1080/03067319408034093, 1994. 
Lawson, D. R., Biermann, H. W., Tuazon, E. C., Winer, A. M., Mackay, G. I., Schiff, H. I., Kok, G. L., Dasgupta, P. K., and Fung, K.: Formaldehyde Measurement Methods Evaluation and Ambient Concentrations During the Carbonaceous Species Methods Comparison Study, Aerosol Sci. Technol., 12, 64-76, doi:10.1080/02786829008959326, 1990.

Lei, W., Zavala, M., de Foy, B., Volkamer, R., Molina, M. J., and Molina, L. T.: Impact of primary formaldehyde on air pollution in the Mexico City Metropolitan Area, Atmos. Chem. Phys., 9, 2607-2618, doi:10.5194/acp-9-2607-2009, 2009.

Li, J. Z., Dasgupta, P. K., and Luke, W.: Measurement of gaseous and aqueous trace formaldehyde - Revisiting the pentanedione reaction and field applications, Anal. Chim. Acta, 531, 51-68, doi:10.1016/j.aca.2004.09.087, 2005.

Li, M., Shao, M., Li, L. Y., Lu, S. H., Chen, W. T., and Wang, C.: Quantifying the ambient formaldehyde sources utilizing tracers, Chin. Chem. Lett., 25, 1489-1491, doi:10.1016/j.cclet.2014.07.001, 2014.

Nowak, J. B., Huey, L. G., Russell, A. G., Tian, D., Neuman, J. A., Orsini, D., Sjostedt, S. J., Sullivan, A. P., Tanner, D. J., Weber, R. J., Nenes, A., Edgerton, E., and Fehsenfeld, F. C.: Analysis of urban gas phase ammonia measurements from the 2002 Atlanta Aerosol Nucleation and Real-Time Characterization Experiment (ANARChE), J. Geophys. Res. Atmos., 111, D17308, doi:10.1029/2006JD007113, 2006.

Olaguer, E. P., Herndon, S. C., Buzcu-Guven, B., Kolb, C. E., Brown, M. J., and Cuclis, A. E.: Attribution of primary formaldehyde and sulfur dioxide at Texas City during SHARP/formaldehyde and olefins from large industrial releases (FLAIR) using an adjoint chemistry transport model, J. Geophys. Res. Atmos., 118, 11317-11326, doi:10.1002/jgrd.50794, 2013.

Parrish, D. D., Ryerson, T. B., Mellqvist, J., Johansson, J., Fried, A., Richter, D., Walega, J. G., Washenfelder, R. A., de Gouw, J. A., Peischl, J., Aikin, K. C., McKeen, S. A., Frost, G. J., Fehsenfeld, F. C., and Herndon, S. C.: Primary and secondary sources of formaldehyde in urban atmospheres: Houston Texas region, Atmos. Chem. Phys., 12, 3273-3288, doi:10.5194/acp-12-32732012, 2012.

Pikelnaya, O., Flynn, J. H., Tsai, C., and Stutz, J.: Imaging DOAS detection of primary formaldehyde and sulfur dioxide emissions from petrochemical flares, J. Geophys. Res. Atmos., 118, 87168728, doi:10.1002/jgrd.50643, 2013.

Pinto, J. P., Dibb, J., Lee, B. H., Rappenglück, B., Wood, E. C., Levy, M., Zhang, R. Y., Lefer, B., Ren, X. R., Stutz, J., Tsai, C., Ackermann, L., Golovko, J., Herndon, S. C., Oakes, M., Meng, Q. Y., Munger, J. W., Zahniser, M., and Zheng, J.: Intercomparison of field measurements of nitrous acid (HONO) during the SHARP campaign, J. Geophys. Res. Atmos., 119, 5583-5601, doi:10.1002/2013JD020287, 2014.

Rappenglück, B., Dasgupta, P. K., Leuchner, M., Li, Q., and Luke, W.: Formaldehyde and its relation to $\mathrm{CO}, \mathrm{PAN}$, and $\mathrm{SO}_{2}$ in the Houston-Galveston airshed, Atmos. Chem. Phys., 10, 2413 2424, doi:10.5194/acp-10-2413-2010, 2010.

Rappenglück, B., Lubertino, G., Alvarez, S., Golovko, J., Czader, B., and Ackermann, L.: Radical precursors and related species from traffic as observed and modeled at an urban highway junction, J. Air Waste Manage., 63, 1270-1286, doi:10.1080/10962247.2013.822438, 2013.
Schripp, T., Fauck, C., and Salthammer, T.: Interferences in the determination of formaldehyde via PTR-MS: What do we learn from $m / z$ 31?, Int. J. Mass Spectrom., 289, 170-172, doi:10.1016/j.ijms.2009.11.001, 2010.

Schultz, M. G., Diehl, T., Brasseur, G. P., and Zittel, W.: Air pollution and climate-forcing impacts of a global hydrogen economy, Science, 302, 624-627, doi:10.1126/science.1089527, 2003.

Seco, R., Penuelas, J., and Filella, I.: Short-chain oxygenated VOCs: Emission and uptake by plants and atmospheric sources, sinks, and concentrations, Atmos. Environ., 41, 2477-2499, doi:10.1016/j.atmosenv.2006.11.029, 2007.

Tromp, T. K., Shia, R.-L., Allen, M., Eiler, J. M., and Yung, Y. L.: Potential environmental impact of a hydrogen economy on the stratosphere, Science, 300, 1740-1742, doi:10.1126/science.1085169, 2003.

Tuazon, E. C., Winer, A. M., and Pitts, J. N.: Trace pollutant concentrations in a multiday smog episode in the California South Coast Air Basin by long path length Fourier transform infrared spectroscopy, Environ. Sci. Technol., 15, 1232-1237, doi:10.1021/es00092a014, 1981.

Vlasenko, A., Macdonald, A. M., Sjostedt, S. J., and Abbatt, J. P. D.: Formaldehyde measurements by Proton transfer reaction - Mass Spectrometry (PTR-MS): correction for humidity effects, Atmos. Meas. Tech., 3, 1055-1062, doi:10.5194/amt-3-1055-2010, 2010.

Volkamer, R., Sheehy, P., Molina, L. T., and Molina, M. J.: Oxidative capacity of the Mexico City atmosphere - Part 1: A radical source perspective, Atmos. Chem. Phys., 10, 6969-6991, doi:10.5194/acp-10-6969-2010, 2010.

Wagner, T. and Wyszynski, M. L.: Aldehydes and ketones in engine exhaust emissions - A review, P. I. Mech. Eng. D-J. Aut., 210, 109-122, doi:10.1243/pime_proc_1996_210_252_02, 1996.

Wang, L., Khalizov, A. F., Zheng, J., Xu, W., Ma, Y., Lal, V., and Zhang, R.: Atmospheric nanoparticles formed from heterogeneous reactions of organics, Nat. Geosci., 3, 238-242, doi:10.1038/ngeo778, 2010.

Wang, M., Shao, M., Chen, W., Yuan, B., Lu, S., Zhang, Q., Zeng, L., and Wang, Q.: A temporally and spatially resolved validation of emission inventories by measurements of ambient volatile organic compounds in Beijing, China, Atmos. Chem. Phys., 14, 5871-5891, doi:10.5194/acp-14-5871-2014, 2014.

Wang, M., Chen, W. T., Shao, M., Lu, S. H., Zeng, L. M., and Hu, M.: Investigation of carbonyl compound sources at a rural site in the Yangtze River Delta region of China, J. Environ. Sci.-China, 28, 128-136, doi:10.1016/j.jes.2014.12.001, 2015.

Warneke, C., Veres, P., Holloway, J. S., Stutz, J., Tsai, C., Alvarez, S., Rappenglueck, B., Fehsenfeld, F. C., Graus, M., Gilman, J. B., and de Gouw, J. A.: Airborne formaldehyde measurements using PTR-MS: calibration, humidity dependence, intercomparison and initial results, Atmos. Meas. Tech., 4, 23452358, doi:10.5194/amt-4-2345-2011, 2011.

Wisthaler, A., Apel, E. C., Bossmeyer, J., Hansel, A., Junkermann, W., Koppmann, R., Meier, R., Muller, K., Solomon, S. J., Steinbrecher, R., Tillmann, R., and Brauers, T.: Technical Note: Intercomparison of formaldehyde measurements at the atmosphere simulation chamber SAPHIR, Atmos. Chem. Phys., 8, 2189 2200, doi:10.5194/acp-8-2189-2008, 2008.

Zheng, J., Zhang, R., Fortner, E. C., Volkamer, R. M., Molina, L., Aiken, A. C., Jimenez, J. L., Gaeggeler, K., Dommen, J., Du- 
santer, S., Stevens, P. S., and Tie, X.: Measurements of $\mathrm{HNO}_{3}$ and $\mathrm{N}_{2} \mathrm{O}_{5}$ using ion drift-chemical ionization mass spectrometry during the MILAGRO/MCMA-2006 campaign, Atmos. Chem. Phys., 8, 6823-6838, doi:10.5194/acp-8-6823-2008, 2008.

Zheng, J., Khalizov, A., Wang, L., and Zhang, R.: Atmospheric pressure-ion drift chemical ionization mass spectrometry for detection of trace gas species, Anal. Chem., 82, 7302-7308, doi:10.1021/ac101253n, 2010.

Zheng, J., Garzón, J. P., Huertas, M. E., Zhang, R., Levy, M., Ma, Y., Huertas, J. I., Jardón, R. T., Ruíz, L. G., Tan, H., and Molina, L. T.: Volatile organic compounds in Tijuana during the Cal-Mex 2010 campaign: Measurements and source apportionment, Atmos. Environ., 70, 521-531, doi:10.1016/j.atmosenv.2012.11.030, 2013a.

Zheng, J., Zhang, R., Garzón, J. P., Huertas, M. E., Levy, M., Ma, Y., Torres-Jardón, R., Ruiz-Suárez, L. G., Russell, L., Takahama, S., Tan, H., Li, G., and Molina, L. T.: Measurements of formaldehyde at the U.S.-Mexico border during the CalMex 2010 air quality study, Atmos. Environ., 70, 513-520, doi:10.1016/j.atmosenv.2012.09.041, 2013b.
Zheng, J., Ma, Y., Chen, M., Zhang, Q., Wang, L., Khalizov, A. F., Yao, L., Wang, Z., Wang, X., and Chen, L.: Measurement of atmospheric amines and ammonia using the high resolution timeof-flight chemical ionization mass spectrometry, Atmos. Environ., 102, 249-259, doi:10.1016/j.atmosenv.2014.12.002, 2015a.

Zheng, J., Yang, D., Ma, Y., Chen, M., Cheng, J., Li, S., and Wang, M.: Development of a new corona discharge based ion source for high resolution time-of-flight chemical ionization mass spectrometer to measure gaseous $\mathrm{H}_{2} \mathrm{SO}_{4}$ and aerosol sulfate, Atmos. Environ., 119, 167-173, doi:10.1016/j.atmosenv.2015.08.028, 2015b. 